NBER WORKING PAPER SERIES

\title{
TARGETS AND INSTRUMENTS OF MONETARY POLICY
}

Benjamin M. Friedman

Working Paper No. 2668

NATIONAL BUREAU OF ECONOMIC RESEARCH

1050 Massachusetts Avenue

Cambridge, MA 02138

July 1988

This research is part of NBER's research program in Financial Markets and Monetary Economics. Any opinions expressed are those of the author not those of the National Bureau of Economic Research. 
NBER Working Paper \#2668

July 1988

TARGETS AND INSTRUMENTS OF MONETARY POLICY

\section{ABSTRACT}

The notion of targets and instruments is basic to the conceptual framework that economists hava used to bring economic analysis to bear on practical issues of how central banks can and/or should conduct monetary policy. This paper surveys the literature of targets and instruments of monetary policy, focusing primarily on the progression of analytical developments during the past two The two issues that have been most central to this entire line of research are the "instrument problem" - - what price or quantity the central bank should fix directly through its open market operations - - and the "intermediate target problem" - . what role (if any) the central bank should assign to variables that it cannot set directly but over which it can exert substantial influence (the most obvious example, of course, being the money stock). Other issues that have figured prominently in this literature include how best to control money growth, should the central bank choose to do so; the potential role of money, credit, and other financial variables as sources of information that might guide the central bank's operations; the implications of alternative policy frameworks for the information available to the economy's private sector: the positive empirical question of determining when and whether any given central bank has actually based its operations on one kind of targeting strategy or another; and the empirical basis for making normative choices among different targets and instruments. The survey concludes by drawing connections to some broader issues, including rules versus discretion and activism versus nonresponsiveness, as well as to the long-standing issue "why money?"

Benjamin M. Friedman

Department of Economics Harvard University Littauer Center 127 Cambridge, MA 02138 


\title{
TARGEIS AND INSTRUMENTS OF MONETARY POLICY
}

\author{
Benjamin M. Friedman* \\ Harvard University
}

The desire to provide normative guidance to public policy is a fundamental theme that has motivated much of monetary economics, almost since the inception of the subject as a recognizable field of economic inquiry. The connection is readily understandable. Because "money" in any modern economy is a commodity either provided by government or, at the least, provided by the private sector under authority and conditions set by government, the link connecting monetary influences on economic activity to specific actions by identifiable public institutions is immediate and direct. Investigating how those public institutions' actions affect the principal dimensions of macroeconomic activity has traditionally constituted the heart of what monetary economics is all about. As long as some macroeconomic outcomes are clearly preferable to others -. stable prices rather than inflation, for example, or prosperity rather than widespread unemployment - the question of what government actions are more likely to lead to more desirable outcomes is not just natural but inevitable.

The literature of targets and instruments of monetary policy has evolved in response to the desire to bring monetary economics even closer to the actual operations of central banks. Following the vocabulary made familiar in a broader policy context by Tinbergen (1952) and others at the outset of the post World War II period, research on the subject has proceeded from the distinction between prices or quantities that a central bank can uniquely determine, 
directly through its own operations (the "instruments" of monetary policy), and those aspects of economic activity that it intends for its operations, along with other elements of public policy as well as independent forces, to affect (the "targets"). In addition, because of the role often advocated in the specific context of monetary policy for economic variables that neither fall under the central bank's direct control nor possess social significant on their own - the leading example, of course, is the stock of money or its rate of growth - the literature has also emphasized yet a third category of prices or quantities now commonly understood as "intermediate targets."

The apparent practical importance of this line of research has increased significantly during the course of the post-war period, as central banks around the world have demonstrated their willingness not merely to change the conceptual framework underlying their monetary policy operations but, indeed, to do so in response both to abstract analysis and to the associated empirical research which it has spawned. This process gained momentum in the 1970s, as many central banks adopted different forms of monetary aggregate targets, and it has continued in the 1980 s as the growing disenchantment with such targets has created a conceptual vacuum at the core of the monetary policy process in many countries. At the same time, specific new questions raised by the application of these ideas to actual policy operations have continued throughout this period to provide fresh ground for new research, so that the interaction between policy practice and policy research has been a two-way influence.

Notwithstanding this quite practical orientation, the literature of targets and instruments of monetary policy also bears fundamental connections to a variety of broader economic and political questions. Most obvious among these are the issues of rules versus discretion, and of an active versus a passive orientation, in economic policy more generally. ${ }^{1}$ For example, having a specific 
institutionalized target regularizes monetary policy responses to entire categories of independent influences and events. Whether a target implies some kind of rule even more broadly, however, and if so whether the rule is necessarily simple and rnnresponsive, remain open and serious questions. In addition, as is frequently the case in debates of rules versus discretion ("government by laws versus government by men"), a motivation often advanced for some kinds of monetary policy targets is to provide a mechanism for holding economic policymakers politically accountable.

This paper surveys the major conceptual developments in the literature of targets and instruments of money policy, with particular emphasis on the broader, "strategic" issues defining the overall framework within which policy operates. The paper therefore devotes less attention to empirical findings and to more detailed questions about institutional arrangements, both of which have tended, on the whole, to be a good deal more specific to the case of individual countries. $^{2}$ Another limitation worth noting at the outset is that this paper focuses primarily on the analysis of monetary policy in closed economies. ${ }^{3}$ Section I examines "the instrument problem" - that is, the selection of the specific price or quantity which the central bank directly and immediately controls -- beginning with the standard analysis introduced by Poole (1970) comparing the relative merits in this context of interest rates and monetary aggregates. A central issue that goes beyond Poole's demand-side-only analysis arises, however, as soon as behavior governing the supply of goods and services also matters in a nontrivial way. It is then necessary first to resolve such prior questions as whether systematic monetary policy affects just nominal magnitudes or also affects real economic activity, and, in turn, to determine the appropriate objective to be pursued by monetary policy. Extension of the Poole analysis to models including a role for aggregate supply behavior hinges 
crucially on such matters.

Section II considers the implications of the fact that what most people mean by "money" in discussions of monetary policy is not a plausible policy instrument at all because it is endogenous in the kind of fractional reserve banking system common to most modern market economies. Hence money is at best an "intermediate target" of monetary policy. Under what circumstances is it useful to have a monetary policy based on money - or, for that mater, any analogous endogenous variable - as an intermediate target? If an economy's reality does not meet these conditions, is there any other role for such endogenous variables in the monetary policy process?

Section III turns to the subsidiary issue, which has been of great practical importance at various times and in various countries, of how the central bank can best control a monetary aggregate should it choose to do so. In part the issues here are analogous to those that arise in the poole analysis and extensions to it, but the literature of this subject has also prominently featured questions about the structure of the fractional reserve banking system which renders money endogenous in the first place. Such practical issues as what constitutes the best short-run forecasting process, and what degree of monetary control generates undesirable side effects like interest rate volatility or even potential dynamic instability, have also been important here.

Section IV reviews more briefly several specific issues that have also arisen within the literature of targets and instruments of monetary policy. These include the implications of alternative monetary policy frameworks for the information available to the economy's private sector, the positive empirical question of when and whether any given central bank has actually based its operations on one kind of targeting strategy or another, and the empirical basis for making normative selections of monetary policy targets and instruments. 
Section $\mathrm{V}$ briefly draws connections to some broader issues, including rules versus discretion and activism versus nonresponsiveness, as well as to the long-standing issue "why money?" 


\section{The Instrument Problem}

A central bank operating in a modern fractional reserve banking system typically has several different tools at its disposal for affecting private economic and financial behavior. In most economies these include the ability to determine (usually within legislatively specified limits) what reserves banks and other depository institutions must hold in relation to their deposits, to vary the supply of such reserves by buying and selling securities (usually' government securities) for the central bank's own account, to lend reserves directly to banks, to set minimum conditions for particular kinds of credit transactions (for example, stock market margin requirements), and to regulate a variety of aspects of ordinary banking and other financial activities. 4 Among these several devices, the buying and selling of securities - - usually called "open market operations" - - is typically the primary focus of the monetary policy function. 5

The "instrument problem" of monetary policy arises because of the need to specify how the central bank will conduct its open market operations. In particular, the instrument problem is the choice of a variable to be set directly by the central bank via buying and selling securities, and hence the value of which is to serve as the principal guide in carrying out that buying and selling function. Because open market operations are in essence a trading activity, the instrument variable used may be either a quantity or a price. The central bank may buy or sell a specified amount of securities, thereby inelastically providing or withdrawing that amount of bank reserves. Alternatively, it may buy or sell whatever amount of securities other traders in the market want to transact at a specified price, thereby elastically letting "the market" determine the quantity of reserves to be held at that price. Beyond this more fundamental choice, of course, it is also necessary for the 
central bank to decide exactly which quantity variable it is setting (for example, total reserves, nonborrowed reserves, the monetary base, reserves or the monetary base adjusted for changes in reserve requirements, and so on), or, alternatively, just which price variable (for example, the interest rate on overnight interbank reserve borrowings, the Treasury bill rate, and so forth).

Whether to key open market operations to a quantity or a price is an issue of first-order importance in normative monetary economics, and has been so for a long time. ${ }^{6}$ The modern literature of the subject dates from the formalization by Poole (1970) of the insight that the optimal choice between quantity and price in this context depends both on familiar parameters describing economic behavior and on the relative magnitudes of the different sources of uncertainty affecting the economy. 7 In the context of the instrument problem -. in contrast to the intermediate target problem, which is the subject of section II below -. Poole's analysis related the choice between exogenously setting a monetary quantity and exogenously setting an interest rate to the relative magnitudes of the unpredictable elements of the nonbank public's behavior in the market for goods and services and the market for financial assets, respectively.

\section{Models Based Only on Aggregate Demand}

Poole's analysis relied on a simplified one-period Hicks-Keynes framework including an aggregate spending (IS) relation and an aggregate money demand (LM) relation,

$$
\begin{aligned}
& y=-\alpha_{1} r+u \\
& m-\beta_{1} y-\beta_{2} r+v
\end{aligned}
$$


where $y$ is income; $m$ is "money," supplied by central bank securities sales and withdrawn by securities purchases; $r$ is the interest rate (the price of the securities bought and sold); $u$ and $v$ are zero-mean disturbances to aggregate spending and money demand, respectively, with variances $\sigma_{u}^{2}$ and $\sigma_{v}^{2}$ and covariance $\sigma_{u v} ;$ coefficients $\alpha_{1}, \beta_{1}$ and $\beta_{2}$ are all non-negative; and all variables are in natural logarithms, so that (with constant terms omitted) they bear the interpretation of deviations from deterministic base values. ${ }^{8}$ Here disturbances $u$ and $v$ reflect not only the stochastic character of private spending and money demand behavior but also any other uncertainties due to influences on such behavior from fiscal or other policy actions, changes in asset values, events abroad, or any other factors assumed to be independent of monetary policy actions.

The model consisting of (1) and (2) is prototypical of the vehicles used for formal analysis of this kind, in that the number of solvable restrictions exceeds by one the number of potentially endogenous variables, so that there is one degree of freedom left to represent the cholce of a policymaker. On the assumption that the central bank's objective is to stabilize income around its deterministic normal value, and that the values of all coefficients are known, this model has the solution

$$
\left.E\left(y^{2}\right)\right|_{r}-\sigma_{u}^{2}
$$

when the interest rate is exogenous, and

$$
\left.E\left(y^{2}\right)\right|_{m}=\frac{\beta_{2}^{2} \sigma_{v}^{2}+\alpha_{1}^{2} \sigma_{v}^{2}-2 \alpha_{1} \beta_{2} \sigma_{u v}}{\left(\alpha_{1} \beta_{1}+\beta_{2}\right)^{2}}
$$


$-9-$

when the money stock is exogenous.

Comparison of (3) and (4) clearly indicates the nature of the trade-off involved in choosing the instrument of monetary policy. Fixing the interest rate - that is, supplying money perfectly elastically - shields income from any disturbances affecting portfolio behavior but provides no protection against disturbances to spending behavior. By contrast, inelastically fixing the money stock forces the interest rate to rise or fall so as partially to damp the impact of disturbances to spending, with the extent of damping given by $0<\frac{\beta_{2}^{2}}{\left(\alpha_{1} \beta_{1}+\beta_{2}\right)^{2}}<1$, but only at the cost of exposing income to disturbances to portfolio behavior. Given values of the three "slope" coefficients (and the correlation between the two disturbances), a larger variance of disturbances to spending relative to disturbances to portfolio behavior therefore makes the money stock more likely to be the preferable instrument, and vice versa. ${ }^{9}$ In the end, however, the choice is inherently empirical. Which instrument is preferable, in the sense of delivering a smaller variance for income, depends on the values of the two respective variances (and the covariance) as well as on the values of the model's three behavioral parameters.

The choice of either instrument amounts to a rule requiring, at least for the single time period under consideration, specified responses of open market operations to the two classes of disturbances under study. From the standpoint of the price of securities, money as the instrument means varying the price in response to either form of disturbance, while the interest rate as the instrument means varying the price in response to neither. From the perspective of the quantity of securities, the interest rate as the instrument means buying or selling in response to either form of disturbance, while money as the instrument means - - subject to the qualification below -- buying or selling in 
response to neither.

Poole also demonstrated that, if the central bank is able to implement a more richly structured response system, in general there exists a policy rule that dominates either the simple interest rate instrument or the simple money stock instrument. In particular, supplying money neither perfectly elastically nor perfectly inelastically but rather according to a more general relation of the form (again omitting the constant term)

$$
m=\gamma_{1} r
$$

for the optimal choice of $\gamma_{1}$, delivers a value of $E\left(y^{2}\right)$ at least as small as the smaller of $\left.E\left(y^{2}\right)\right|_{r}$ and $\left.E\left(y^{2}\right)\right|_{m}$. The solution for the optimal elasticity of money supply is

$$
\gamma_{1}-\frac{-\beta_{1} \beta_{2} \sigma_{\mathrm{v}}^{2}+\alpha_{1} \sigma_{\mathrm{v}}^{2}+\left(\alpha_{1} \beta_{1}-\beta_{2}\right) \sigma_{\mathrm{uv}}}{\beta_{1} \sigma_{\mathrm{v}}^{2}+\sigma_{\mathrm{uv}}}
$$

for which the value of the objective is

$$
\left.E(y)^{2}\right|_{\gamma_{1}}-\frac{\sigma_{\mathrm{u}}^{2} \sigma_{\mathrm{v}}^{2}\left[1-\left(\frac{\sigma_{\mathrm{uv}}}{\sigma_{\mathrm{u}} \sigma_{\mathrm{v}}}\right)^{2}\right.}{\beta_{1}^{2} \sigma_{\mathrm{v}}^{2}+\sigma_{\mathrm{v}}^{2}+2 \beta_{1} \sigma_{\mathrm{uv}}}
$$

The greater generality of the finite-elasticity response policy is readily apparent in that use of the interest rate as a straight instrument $\left(\gamma_{1}-\infty\right)$ follows for $\sigma_{u}^{2}-0$ (and, of course, then $\sigma_{u v}-0$ ), while use of money as a straight instrument follows for combinations of values of $\sigma_{\mathrm{u}}^{2}$ and $\sigma_{\mathrm{v}}^{2}$ (and $\sigma_{\mathrm{uv}}$ ) 
for which $\gamma_{1}=0$.

Apart from these two special cases, the central bank's optimal policy amounts to closing Poole's three-variable-two-restriction model by adding a third nontrivial restriction, rather than by taking a unique variable as exogenous. Morever, inspection of (6) shows that, even apart from effects due to the covariance of the two disturbances, it is impossible to say a priori whether this optimal response policy is to supply money with positive or negative interest elasticity. The choice is again empirical. In intuitive terms, the optimal money supply response amounts to whatever is necessary to offset the slope and variation in money demand behavior, so as to render the model's solved-out money market equilibirum as nearly interest inelastic as possible - in other words, to produce a vertical LM curve. 10

The Poole analysis in this general form has proved highly useful in a variety of different settings, including not just monetary policy issues but such questions as fixed versus flexible exchange rates and nominal versus indexed wages. 11 The common features of this kind of analysis include the relation of a policy choice to the relative variances of different sources of uncertainty affecting the relevant aspects of economic behavior, the dependence of optimal actions also on key behavioral parameters, and the dominance in general of optimally structured constraints over simply fixing one variable or another. A key part of its contribution has been to establish the inescapably empirical nature of policy questions like those under study here.

\section{Supply-Demand Mode1s with Neutral Monetary Policy}

At least since the mid 1970s, when the effects of price increases imposed by the international petroleum cartel greatly increased macroeconomists' interest in many aspects of aggregate supply behavior, a major thrust of the 
literature of targets and instruments of monetary policy has been to move beyond a demand-only framework to models incorporating nontrivial representations of aggregate supply. Extending Poole's analysis to a complete supply-demand context is not straightforward, however. One reason is that doing so immediately raises the issue of whether systematic monetary policy is or is not neutral, in the sense of affecting only nominal magnitudes while leaving real economic activity unchanged. Moreover, in models in which monetary policy does affect both nominal and real magnitudes, there is no ready analog to the obvious policy objective of stabilizing "income" in Poole's model.

For models in which monetary policy is neutral, Sargent and Wallace (1975) demonstrated that the classic choice between money and the interest rate as the exogenous policy variable is really no choice at all in that, with rational expectations, prices in the goods and services market are indeterminate under an interest rate instrument. A simplified version of Sargent and Wallace's model expands Poole's IS-LM framework both by adding the representation of aggregate supply behavior due to Lucas $(1972,1973)$ and by distinguishing between real and nominal magnitudes for both quantity variables and interest rates. The resulting three-equation-four-variable model is then

$$
\begin{aligned}
& x_{t}--\alpha_{1}\left[r_{t}-\left(E_{t-1}\left(p_{t+1}\right)-p_{t}\right)\right]+u_{t} \\
& m_{t}=p_{t}-\beta_{1} x_{t}-\beta_{2} r_{t}+v_{t} \\
& x_{t}=\gamma_{1}\left(p_{t}-E_{t-1}\left(p_{t}\right)\right)+\gamma_{2} x_{t-1}+z_{t}
\end{aligned}
$$

where $x$ now denates real output and spending; $p$ is the price level; $r$ is specifically the nominal interest rate; $z$ is a zero-mean disturbance to. 
aggregate supply, with variance $\sigma_{z}^{2} ; E_{t-1}$ denotes the expectation operator conditional on information as of time $t-1$; and all variables are again in logarithms, and all constants are omitted.

Because of the structure of (10), with its imposition of a "natural rate" of output except for price misperceptions and the random disturbance $z$, any predetermined nonstochastic value of $m_{t}$ that economic agents are assumed to incorporate into expectations $E_{t-1}(\cdot)$ affects neither the expected value nor any other aspect of the distribution describing $x_{t}$. Monetary policy is neutral. 12 Money is a plausible instrument variable; but it affects prices only, not real output.

By contrast, the model simply breaks down if the exogenous policy instrument is not money but the interest rate. In that case, the model's real variables are overdetermined, while there exists an extra degree of freedom in the solution for all nominal magnitudes. Both the price level and the nominal money stock are indeterminate. Unless prices are of no concern to policymakers at all, therefore, the Sargent-Wallace analysis indicates that the interest rate instrument is not just inferior but implausible on an a priori basis. Unlike in Poole's analysis, the instrument problem is not an empirical issue.

McCallum (1981) subsequently demonstrated, however, that this indeterminancy of prices under an interest rate instrument would follow only in the case in which the central bank's ultimate objective placed no weight at all on prices - - what McCallum turned a "pure interest rate peg." By contrast, as long as the central bank places at least some weight on prices in formulating monetary policy, the model does yield a determinate solution for all variables. McCallum actually showed this result for the case in which the central bank's objectives include money, rather than prices, so that the interest rate is exogenously set as a linear combination of an arbitrary value ( $r_{t-1}$ in 
McCallum's example based on a preference for interest rate smoothing over time) and the value consistent with any arbitrarily selected value for the money stock, and hence the policy rule is

$$
r_{t}=\phi r_{t}^{*}+(1-\phi) r_{t-1}
$$

where $r_{t}^{*}$ is $r_{t}$ such that $E_{t-1}\left(m_{t} \mid r_{t}\right)=m_{t}^{*}$ for $m_{t}^{*}$ arbitrary. It is clear, however, that McGallum's result carries over to the case in which the central bank's objective includes not just money but any nominal variable. For example, a joint preference for smooth interest rates and stable prices, which would again imply (11) where $r_{t}^{*}$ is instead $r_{t}$ such that $E_{t-1}\left(p_{t} \mid r_{t}\right)-p_{t-1}$, would work just as well. At an intuitive level, the Sargent-Wallace indeterminancy result simply amounts to the point that there must be some nominal anchor to determine the absolute price level in any economy. Exogenously fixing the nominal money stock is one way to provide such an anchor, but there are also many others.

\section{Supply-Demand Models with Non-neutral Monetary Policy}

Even in models based on rational expectations and aggregate supply behavior that exhibits the natural rate property, systematic monetary policy may affect real economic activity for a variety of reasons. Following the early contributions of Fischer (1977a) and Phelps and Taylor (1977), the literature has primarily emphasized failures of neutrality due to less than perfectly flexible wages and/or prices. At its most basic level, the point has long been familiar. An economy needs a nominal anchor to determine its absolute price level, but it does not need two of them. Money can only be neutral if it is the only exogenously set nominal variable. 13

The immediate effect of introducing some inflexibility to either wages or 
prices in this context is to alter the aggregate supply function. For example, Fischer's equivalent to a reduced form for (8)-(10), based on two-period nominal wage contracts and assuming $\gamma_{1}-1$ for simplicity, is

$$
x_{t}-\frac{1}{3} m_{t}+\frac{1}{2}\left(e_{1 t}+e_{2 t}\right)+\frac{1}{6} E_{t-1}\left(e_{1 t}-e_{2 t}\right)+\frac{1}{3} E_{t-2}\left(e_{1 t}-e_{2 t}\right)
$$

where $e_{1}$ is the disturbance to aggregate supply expressed as a function of the real wage, and $e_{2}$ is the disturbance to aggregate demand expressed as a function of real balances (that is, a solved-out form of (8) and (9)) with elasticity also assumed equal to one. Phelps and Taylor's equivalent, based on a model with prices fixed one period in advance, is

$$
: \quad x_{t}=\theta_{1}\left(E_{t-1}\left(p_{t}\right)-p_{t-1}\right)+\theta_{2}\left(m_{t}-p_{t-1}\right)+e_{t}
$$

where $\theta_{1}$ and $\theta_{2}$ are combinations of the coefficients in their model's underlying behavioral equations, and $e$ is a combination of the disturbances in these equations. Still another variant that has figured prominently in the literature of targets and instruments of monetary policy is Bean's (1983)

$$
x_{t}=\gamma_{1}\left[\left(p_{t}-E_{t-1}\left(p_{t}\right)\right)+\gamma_{2} E_{t-1}\left(z_{t}\right)\right]+\gamma_{3} z_{t}
$$

where $z$ is now the technological disturbance to an underlying Cobb-Douglas production function, and the three coefficients bear the structural interpretations

$$
\begin{aligned}
& \gamma_{1}=\frac{1-\phi}{\phi} \\
& \gamma_{2}=\frac{\theta}{\phi+\theta}
\end{aligned}
$$




$$
\gamma_{3}=\frac{1}{\phi}
$$

where $-\frac{1}{\phi}$ is the wage elasticity of labor demand (in other words, where (1- $\phi$ ) is the labor coefficient in the production function), and $\frac{1}{\theta}$ is the wage elasticity of labor supply. Yet another variant prominently used in the analysis of monetary policy is Turnovsky's (1987)

$$
x_{t}=\gamma_{1}\left(p_{t}-E_{t-1}\left(p_{t}\right)\right)+\gamma_{2} E_{t-1}\left(z_{t}\right)+\gamma_{3} E_{t}\left(z_{t}\right)+z_{t}
$$

where the coefficients bear the structural interpretation

$$
\begin{aligned}
& \gamma_{1}=\gamma_{3}(1-r) \\
& \gamma_{2}=\gamma_{3}\left(\frac{\theta}{\theta+\phi}\right) \\
& \gamma_{3}=\frac{1-\phi}{\phi}
\end{aligned}
$$

where $-\frac{1}{\phi}$ and $\frac{1}{\theta}$ are again the wage elasticities of 1 abor demand and labor supply, respectively; $\tau$ is the extent to which wages are indexed to prices, $0 \leq r \leq 1$; and $E_{t}\left(z_{t}\right)$ indicates the contemporaneous perception of $z_{t}$, which may or may not equal $z_{t}$.

Any of these supply functions renders monetary policy nonneutral, even under rational expectations, so that further analysis of the instrument problem requires a particular policy objective specifying the weight placed on real versus nominal targets. Perhaps for that reason - and also perhaps because of the widespread dissatisfaction with the results of using interest rates in this role earlier on - - there has been little analysis in the literature examining 
the cholce of monetary policy instrument at this level. Such an analysis is easily possible, however, as an example based on the model used by Aizenmann and Frenkel (1986) - - though carrying out an exercise they did not undertake -. readily illustrates.

In order to establish a plausible objective for monetary policy in the presence of potential disturbances to aggregate supply. Aizenmann and Frenkel based their analysis on maintaining equilibrium in the labor market characterized by labor demand

$$
\ell^{d}-\phi(p-w+z)
$$

and labor supply

$$
\ell^{s}-\theta(w-p)
$$

where $w$ is the (logarithm of the) nominal wage, and $z$ is a zero-mean percentage disturbance to production for given capital and labor. If (18) represents the first-order condition derived from a Cobb-Douglas production function with labor coefficient $\delta$, then $\phi-\frac{1}{1-\delta}$ and the quantity of output is

$$
x=\phi[\delta(p-w)+z]
$$

The corresponding market-clearing equilibrium is invariant to the specification of aggregate demand or to any disturbances affecting aggregate demand, of course, but it does vary with $z$. In particular, $\ell^{d}-\ell^{s}$ implies

$$
(w-p)^{e}-\frac{\phi}{\phi+\theta} z
$$




$$
\begin{aligned}
& \ell^{e}=\theta\left(\frac{\phi}{\phi+\theta}\right) z \\
& x^{e}=(1+\theta)\left(\frac{\phi}{\phi+\theta}\right) z
\end{aligned}
$$

where the e superscript indicates equilibrium values. 14 In the absence of some specific impediment, the ordinary working of the labor market would establish a new equilibrium at these values following the emergence of any non-zero realization of the production disturbance $z$. At the same time, nothing in the equilibration process represented by (21) anchors the value of any nominal magnitude (wages $w$, prices $p$, or nominal income $x+p$ ).

Following Gray (1976), Fisher (1977) and Phelps and Taylor (1977), it is useful to suppose that the impediment which prevents the automatic establishment of the new equilibrium given in (21) is less than perfect flexibility of nominal wages. In the limit, if nominal wages are rigid $(w-0)$, then reaching the equilibrium in (21) requires $p=-\left(\frac{\phi}{\phi+\theta}\right) z$. If the model's demand side is as in (8) and (9), and the zero-mean property of $z$ implies zero expected price inflation in this one-period context, then the monetary policy that exactly delivers the price movement required to achieve the market-clearing real wage despite the rigidity of nominal wages can be expressed equivalently as 15

$$
\mathrm{m}^{\mathrm{e}}=\mathrm{v}-\left(\frac{\beta_{2}}{\alpha_{1}}\right) \mathrm{u}+\left(\frac{\phi}{\phi+\theta}\right)\left[(1+\theta)\left(\beta_{1}-\frac{\beta_{2}}{\alpha_{1}}\right)-1\right] z
$$

or

$$
r-\frac{1}{\alpha_{1}} u-\left(\frac{1+\theta}{\alpha_{1}}\right)\left(\frac{\phi}{\phi+\theta}\right) z
$$


Here the equilibrium movement in the money stock accommodates any disturbance to money demand on a one-for-one basis, fully offsets any disturbance to real aggregate demand (with allowance for the relevant elasticities $\alpha_{1}$ and $\beta_{2}$ ), and responds to the supply disturbance in just the fashion necessary to deliver $p=-\left(\frac{\phi}{\phi+\theta}\right) z^{16}$ The erililibrium movement in the interest rate does not depend at all on the money demand disturbance, but it again fully offsets any real aggregate demand disturbance (with allowance for $\alpha 1$ ) and it again responds to the supply disturbance so as to deliver $p--\left(\frac{\phi}{\phi+\theta}\right) z$.

Clearly, implementing the monetary policy described by $m^{e}$ or $r$ requires knowledge of the realizations of the model's three disturbance terms (only $u$ and $z$ in the case of $r^{e}$ ). In the absence of such knowledge, the choice that corresponds to the classic form of the monetary policy instrument problem would be to fix either $m=0$ or $r-0$, consistent with a zero prior expectation for each disturbance. Either $m=0$ or $r=0$, however, delivers values of output, prices, labor input and real wages that will then differ from the corresponding market-clearing equilibrium. In order to evaluate the relative merits of these two policy alternatives in so rich an environment, it is therefore necessary to have a well specified policy objective. For example, if the sole criterion of monetary policy is the variance of output around the equilibrium given in (21), then the solution to the instrument problem hinges on a comparison between

$$
\begin{aligned}
&\left.E\left(x-x^{e}\right)^{2}\right|_{m}-\frac{\beta_{2}^{2}(\phi-1)^{2}}{\lambda^{2}} \sigma_{u}^{2}+\frac{\alpha_{1}^{2}(\phi \cdot 1)^{2}}{\lambda^{2}} \sigma_{v}^{2} \\
&+\left[\frac{\alpha_{1}^{2}\left(\beta_{2}+1\right)^{2}}{\lambda^{2}}-\frac{2 \alpha_{1}\left(\beta_{2}+1\right)(\theta+1)}{\lambda(\phi+\theta)}+\frac{(\theta+1)^{2}}{(\phi+\theta)^{2}}\right] \phi^{2} \sigma_{z}^{2}
\end{aligned}
$$


and

$$
\begin{aligned}
\left.E\left(x-x^{e}\right)^{2}\right|_{r}= & \frac{(\phi-1)^{2}}{\left(\phi-1+\alpha_{1}\right)^{2}} \sigma_{u}^{2}+\left[\frac{\alpha_{1}^{2}}{\left(\phi-1+\alpha_{1}\right)^{2}}-\frac{2 \alpha_{1}(\theta+1)}{\left(\phi-1+\alpha_{1}\right)(\phi+\theta)}\right. \\
& \left.+\frac{(\theta+1)^{2}}{(\phi+\theta)^{2}}\right] \phi_{z}^{2} \sigma_{z}^{2}
\end{aligned}
$$

where $\lambda-\alpha_{1} \beta_{1} \delta \phi+\beta_{2}\left(\alpha_{1}+\delta \phi\right)+\alpha_{1}$, and for simplicity both expressions omit all relevant covariance terms. ${ }^{17}$ Alternatively, if the sole objective of monetary policy is to stabilize output around the deterministic (x - 0) value, rather than around the new market-clearing equilibrium value - - in other words, to avoid fluctuations in output, even in response to real production shocks -the choice between $m-0$ and $r=0$ hinges on the comparison of

$$
\left.\mathrm{E}\left(\mathrm{x}^{2}\right)\right|_{\mathrm{m}}-\frac{\beta_{2}^{2}(\phi-1)^{2}}{\lambda^{2}} \sigma_{\mathrm{u}}^{2}+\frac{\alpha_{1}^{2}(\phi-1)^{2}}{\lambda^{2}} \sigma_{\mathrm{v}}^{2}+\frac{\alpha_{1}^{2}\left(\beta_{2}+1\right)^{2} \phi^{2}}{\lambda^{2}} \sigma_{\mathrm{z}}^{2}
$$

and

$$
\left.E\left(x^{2}\right)\right|_{r}-\frac{(\phi-1)^{2}}{\left(\phi-1+\alpha_{1}\right)^{2}} \sigma_{u}^{2}+\frac{\alpha_{1}^{2} \phi^{2}}{\left(\phi-1+\alpha_{1}\right)^{2}} \sigma_{z}^{2}
$$

where again both expressions omit all covariance terms. Both of these sets of comparisons are clearly empirical matters. 18

While there is no reason to presume that the stabilization of output per se, around either the ex ante or the ex post equilibrium, is necessarily the 
only criterion governing monetary policy, at least some other suggested objectives amount to the same thing. For example, the policy objective suggested by Aizenmann and Frenkel for their own model is equivalent to minimizing the expected area of a triangle representing the welfare loss due to disequilibrium in the labor market in terms of consumers' and producers' surplus. On the assumption that firms are always on their labor demand curves, so that $\ell-\ell^{\mathrm{d}}$ regardless of whether $\ell^{\mathrm{d}} \gtrless \ell^{s}$, that measure for this model is

$$
\Delta=\frac{1}{2}\left(\ell-\ell^{e}\right)\left[(w-p)^{s}-(w-p)\right]
$$

where $(w-p)^{5}$ is the supply price of labor, equal to $\frac{1}{\theta} \ell$ from (19). 19 For this policy objective, however, the solution to the instrument problem simply hinges on the comparison of

$$
\left.E(\Delta)\right|_{m}-\left.\kappa \cdot E\left(x-x^{e}\right)^{2}\right|_{m}
$$

and

$$
\left.E(\Delta)\right|_{r}-\kappa \cdot E\left(x-x^{e}\right)^{2} \mid r
$$

where $\kappa=\frac{\phi(\phi+\theta)}{2 \theta(\phi-1)^{2}}$.

In sum, the basic insight of the Poole analysis - - relating the choice of instrument of monetary policy to the relative variances of different categories of disturbances affecting the economy, as well as to the values of specifically identifiable parameters of economic behavior - carries over to models incorporating nontrivial aggregate supply behavior, as long as there is some 
contradiction of perfectly classical assumptions that prevents the economy from automatically equilibrating on its own in the first place (and, at the same time, renders monetary policy non-neutral.) 20 


\section{The Intermediate Target Problem}

A potentially important problem inherent in the entire mode of analysis reviewed in Section I is that what most people mean by "money" in discussions of monetary policy is not a quantity set directly by the central bank. Under the kind of fractional reserve banking system in use in almost all modern economies in the western world, most of the money used by the public, either as a means of payment or as a liquid store of value, represents the liabilities of private depository institutions. Although the central bank can influence the money-creating activities of these institutions, that influence is not the same as its being able to set the money stock exogenously, as if money were a genuine policy instrument. Instead, the quantity variable which the central bank can set directly, if it chooses, is at best some measure of its own liabilities -. for example, bank reserves or the monetary base (reserves plus currency). One solution to this problem, of course, is simply to define "money" so that it is potentially exogenous - - that is, to define money as some measure of the central bank's direct liabilities - - regardless of common usage. In that case "money demand" functions like (2) or (9) represent the derived demand for central bank liabilities, based on the underlying fractional reserve system (and, if the measure used is the monetary base, on the public's demand for currency), and the analysis can proceed just as before. Nevertheless, this confounding of the respective portfolio behavior of the banking system and the nonbank public runs counter to the rich and long-standing tradition of distinct analysis of money demand behavior (meaning that of the nonbank public) and money supply behavior (meaning that of the banking system). In addition, keeping the two analytically separate in this context as well is more consistent with the principle of distinguishing among the respective implications of disturbances to the economy arising from different sources. 21 
Merely extending the analysis of the instrument problem in Section $I$ to allow for the endogeneity of "money" is fairly straightforward. Following Modigliani, Rasche and Cooper (1970) and others, a standard representation of bank portfolio behavior that can be construed as either the supply of money or the demand for reserves is

$$
m=\delta_{1} h+\delta_{2} r+q
$$

where $h$ is the quantity of nonborrowed reserves (or any other potentially exogenous measure of central bank liabilities), and $q$ is a zero-mean disturbance with variance $\sigma_{q}^{2}{ }^{22}$ The classic instrument problem is then the choice between reserves and the interest rate, rather than between money and the interest rate, as the variable to be set exogenously by monetary policy.

Combining (31) with (1) and (2) gives an expanded version of the demand-only model analyzed in Section $I$, for which the solution is again as in (3) for the interest rate instrument and

$$
\begin{aligned}
\left.E\left(y^{2}\right)\right|_{\mathrm{h}}- & \frac{1}{\left(\alpha_{1} \beta_{1}+\beta_{2}+\delta_{2}\right) 2}\left[\left(\beta_{2}+\delta_{2}\right)^{2} \sigma_{\mathrm{u}}^{2}+\alpha_{1}^{2} \sigma_{\mathrm{v}}^{2}+\alpha_{1}^{2} \sigma_{\mathrm{q}}^{2}\right. \\
& \left.-2 \alpha_{1}\left(\beta_{2}+\delta_{2}\right) \sigma_{\mathrm{uv}}+2 \alpha_{1}\left(\beta_{2}+\delta_{2}\right) \sigma_{\mathrm{uq}}-2 \alpha_{1}^{2} \sigma_{\mathrm{vq}}\right]
\end{aligned}
$$

for the reserves instrument, where $\sigma_{u q}$ and $\sigma_{v q}$ are the covariances of $q$ with $u$ and $v$, respectively. As in the comparison between (3) and (4), the advantage of supplying reserves perfectly inelastically is to damp the effect on income due to disturbances to aggregate demand, with damping factor 
$0<\frac{\left(\beta_{2}+\delta_{2}\right)^{2}}{\left(\alpha_{1} \beta_{1}+\beta_{2}+\delta_{2}\right)^{2}}<1$. The associated disadvantage is that doing so exposes income to effects due to disturbances to both money demand behavior and money supply (reserves demand) behavior, both of which a policy of supplying reserves perfectly elast:ally would eliminate. Similarly, combining (31) with a supply-demand model like that consisting of (8), (9), and (18)-(20) would have analogously straightfoward effects on comparisons like (24) versus (25), or (26) versus (27).

By contrast, the issue that is not straightforward when money is endogenous is what role money itself can or should play in the monetary policy process. The intermediate target problem is the choice of just such a variable, usually a readily observable financial quantity (or price), that the central bank will treat, for purposes of some interim-run time horizon, as if it were the target of monetary policy - - even though everyone recognizes that the quantity (or price) in question actually bears no ultimate significance at all. What it means to base monetary policy on an intermediate target, and under what conditions doing so is sensible, has been the focus of a substantial literature.

\section{General Statement of the Problem}

It is easiest to understand the use of any given intermediate target variable for monetary policy as a two-stage procedure. In the first stage, the central bank determines the value of the intermediate target which would be consistent with the desired ultimate policy objective under a variety of ex ante assumptions - for example, zero values for all relevant disturbances. At the second stage, the central bank proceeds, in some ex post fashion, to treat achieving this value of the intermediate target (set ex ante) if doing so were the objective governing policy. In practice many central banks have implemented 
intermediate target strategies at least approximately according to this two-stage manner.

The distinction between the "ex ante" assumptions employed in the first stage of this process and whatever makes the second stage "ex post" is clearly crucial. Since the passage of time per se is not a significant issue here, the literature analyzing the intermediate target problem has largely focused on the availability of new information as time passes. The key role of the intermediate target variable, then, is to provide a rule for processing and acting on this new information.

Friedman (1977) suggested several plausible circumstances under which money (or, for that matter, any other endogenous variable) may provide such useful information. All arise in a dynamic setting in which a relevant value of the intermediate target variable is observable before some policy decision, or some adjustment to an earlier policy decision, is made, while the corresponding value(s) of the variable(s) constituting the ultimate policy objective are not This realization of the intermediate target is then part of the information set underlying the choice of a final value for the policy instrument.

The most obvious context in which this kind of segmented information flow arises is an inherently dynamic system in which the relevant economic behavior exhibits leads and lags distributed through time. For example, if people demand money for transactions purposes, and tend on average to accumulate money in advance of actual spending, then in general the observed value of the money stock at any time conveys information about the future strength of aggregate demand. Similarly, in models in which some individuals' or businesses' ability to spend depends in part on their ability to borrow, and loan transactions tend to precede actual spending, the observed volume of credit conveys information about the future state of aggregate demand. In either case, such information is 
at least potentially useful whenever monetary policy actions affect economic behavior with a lag.

An endogneous variable like the money stock can also provide such useful information, even in the absence of behavioral economic lags, if there are lags in the availability of relevant data. For example, in a context in which disturbances to economic behavior are serially correlated, observations of the recent values of key endogenous variables convey information that is potentially useful for anticipating future outcomes. If observations of endogenous financial variables like money (or credit, or interest rates) are available on a more timely basis than observations of variables like income and prices - as is the case in most economies - - then the information given by those financial variables in general has a role to play in setting the optimal value of the policy instrument. Equivalently, if observations of financial variables are available continuously throughout the "period" of analysis but observations of variables like income and prices are not, and if it is possible for the central bank to adjust the value of its policy instrument as time passes within the period, then again these available observations in general have a role to play in the policy making process.

Even so, finding that some variable like money conveys potentially useful information is not the same as establishing that the central bank should specifically use that variable as an intermediate target. Much of the literature of the intermediate target problem has focused on analyzing just this distinction.

Intermediate Targets In Models Based Only on Aggregate Demand Friedman (1975, 1977) analyzed the intermediate target problem in the context of a demand-only model consisting of (1), (2) and (31), with serially 
correlated disturbances. For zero expectations of disturbances $u, v$ and $q$, whether the policy that delivers the smaller variance of income in such a model is $r=0$ or $h=0$ depends upon the comparison of (3) and (32). 23 In either case, the potential role in this context for money, an endogenous variable in either case, is to provide information indicating a likely non-zero realization of some relevant disturbance, and therefore - - if this information is in hand in time to react to it - warranting a different value of the policy instrument.

If each of the three disturbances $u, v$ and $q$ follows a first-order autoregressive process with autocorrelations $\rho_{u^{\prime}} \rho_{\mathrm{v}}$ and $\rho_{\mathrm{q}}$, respectively, knowing the values of each of the model's three endogenous variables at $t$ ime $t-1$ facilitates using (1), (2) and (31) to discover the values of $u_{t-1}, v_{t-1}$, and $q_{t-1}$ and then calculating "informed" expectations of the three disturbances for period $t$ as $\rho_{u} u_{t-1}, \rho_{v} v_{t-1}$ and $\rho_{q} q_{t-1}$. The optimal value of the policy instrument for period $t$, given this information, is then

$$
r_{t}=\frac{\rho_{u}}{a_{1}} u_{t-1}
$$

under the interest rate instrument, or

$$
h_{t}=-\frac{1}{\alpha_{1} \delta_{1}}\left[\left(\beta_{2}+\delta_{2}\right) \rho_{u} u_{t-1}-\alpha_{1} \rho_{v} v_{t-1}+\alpha_{1} \rho_{q} q_{t-1}\right]
$$

under the reserves instrument. By contrast, if observations of $m_{t-1}$ and whichever of $r_{t-1}$ or $h_{t-1}$ was endogenous are avaflable, but $y_{t-1}$ remains unknown, it is not possible to solve (1), (2) and (31) for $u_{t-1}, v_{t-1}$ and $q_{t-1}$, and hence not possible to implement either (33) or (34).

Using money as an intermediate target variable in this context amounts to 
setting $r$ or $h$ so as to achieve $E_{t-1}\left(m_{t}\right)=0 .{ }^{24}$ This policy is either

$$
r_{t}-\frac{1}{\alpha_{1} \beta_{1}+\beta_{2}}\left[\frac{\beta_{1}^{2} \rho_{u} \sigma_{u}^{2}+\rho_{v} \sigma_{v}^{2}+\beta_{1}\left(\rho_{u}+\rho_{v}\right) \sigma_{u v}}{\beta_{1}^{2} \sigma_{u}^{2}+\sigma_{v}^{2}+2 \beta_{1} \sigma}\right] m_{t-1}
$$

with an interest rate instrument, or

$$
h_{t}=\frac{\left(\alpha \beta_{1}+\beta_{2}+\delta_{2}\right)}{\delta_{1}\left(\alpha_{1} \beta_{1}+\beta_{2}\right)} \cdot \frac{\omega_{1}}{\omega_{2}} \cdot \mathrm{m}_{t-1}
$$

where $\omega_{1}$ and $\omega_{2}$ are appropriately weighted combinations of all three variances $\sigma_{\mathrm{u}}^{2}, \sigma_{\mathrm{v}}^{2}$ and $\sigma_{\mathrm{q}}^{2}$ ) and all three corresponding covariances, with a reserves instrument. Hence under either instrument the model breaks down in such a way that targeting the money stock in this context requires responding only to the information contained in $m_{t-1}$ but not whichever of $h_{t-1}$ or $r_{t-1}$ is endogenous. The criticism of this policy argued in Friedman (1975) is that in general neither (35) nor (36) is the policy that actually minimizes the variance of income, given the available information contained in the observations $m_{t-1}$ and either $r_{t-1}$ or $h_{t-1}$. The policy that minimizes $E_{t-1}\left(y_{t}^{2}\right)$ is instead either

$$
r_{t}=\frac{1}{\alpha_{1}}\left[\frac{\beta_{1} \rho_{u} \sigma_{u}^{2}+\rho_{u} \sigma_{u v}}{\beta_{1}^{2} \sigma_{u}^{2}+\sigma_{v}^{2}+2 \beta_{1} \sigma_{u v}}\right] \mathrm{m}_{t-1}
$$

or

$$
\mathrm{h}_{\mathrm{t}}=-\frac{\alpha_{1} \beta_{1}+\beta_{2}+\delta_{2}}{\alpha_{2} \delta_{1}} \cdot \frac{\omega_{3}}{\omega_{4}} \cdot \mathrm{m}_{t-1}
$$


where $\omega_{3}$ and $\omega_{4}$ are analogous (though not identical) to $\omega_{1}$ and $\omega_{2}$. Comparison of (35) to (37) (or of (36) to (38)) shows that treating money as an intermediate target of monetary policy does not in general deliver the instrument value consistent with minimizing the variance of income, given the information contained in lagged values of the endogenous financial variables. Under special conditions, of course, the two may be identical. For example, Friedman pointed out that if $\beta_{2}=\sigma_{\mathrm{v}}^{2}=0$ - that is, if money demand is both interest inelastic and nonstochastic - then both (35) and (37) trivially reduce to $r_{t}=-\left(\frac{\rho_{u}}{\alpha_{1} \beta_{1}}\right) m_{t-1}$. In general, however, the policy based on money as an intermediate target variable is not even the best way for monetary policy to take advantage of the information contained in observations of money itself, much less an optimum way of processing all available information in general. 25

Intermediate Targets in Supply-Demand Models

For the same reason that they make the analysis of the instrument problem so straightforward, demand-only models like the one used above offer only limited possibilities for investigation of various intermediate targets of monetary policy. Because "income" is typically the model's only endogenous nonfinancial variable, and hence the obvious ultimate policy target, there is no remaining nonfinancial variable to suggest as an intermediate target. The choice of an intermediate target must therefore be from among the model's set of endogenous financial variables.

Models Incorporating both aggregate supply and aggregate demand behavior also admit analysis of policies based on the use of some financial variable as an intermediate target variable, although the literature has not pursued this aspect of the subject in any depth. 26 For example, making the money stock 
endogenous in a model like that of Aizenmann and Frenkel (1986) would merely require adding a money supply function like (31) to the system consisting of (8), (9) and (18)-(20). The policy of exogenously setting $m-0$, analyzed in Section $I$, would not then be feasible, but treating money as an intermediate target variable - - that $1 \mathrm{~s}$, setting either reserves or the interest rate such that either $E_{t-1}\left(m_{t} \mid r_{t}\right)-0$ or $E_{t-1}\left(m_{t} \mid h_{t}\right)-0$ for any given information set .. would be. Computing the resulting variances corresponding to $E\left(x-x^{e}\right)^{2}$ in (24) and (25), $E\left(x^{2}\right)$ in (26) and (27), or $E(\Delta)$ in (29) and (30), would then be relatively straightforward. The general inferiority of any such policy, compared to the policy of setting either $r$ or $h$ at the value derived by directly minimizing the ultimate policy objective, would emerge in a way that is analogous to the result shown above for the demand-only model.

Analysis of intermediate monetary policy targets within supply-demand models has instead primarily focused on the potential use of nonfinancial variables like prices or nominal income. In this context too, it is crucial to distinguish between analysis based on supply-demand models in which systematic monetary policy is neutral and the contrasting analysis of nonneutral policy. When policy does not affect the distribution of real magnitudes, the price level (or, equivalently, nominal income) becomes the only plausible ultimate macroeconomic policy target. Hence the analysis of price or nominal income targets in such models typically has little if anything to do with the intermediate target problem. By contrast, when policy does affect real magnitudes, a price target for monetary policy is clearly an intermediate target (unless real variables receive no weight at all in policymakers preferences), and a nominal income target is also an Intermediate target unless the ultimate policy objective also exhibits the one-for-one weighting system implicit in the $y=x+p$ definition. 27 
Aizenmann and Fenkel (1986), for example, analyzed both a price target and a nominal income target as if these variables were potential policy instruments - that is, on the assumption that either $p=0$ or $x+p=0$ in the model used above could be set exogenously. They showed that, in their model with nominal wages rigid, fixing nominal income is equivalent to holding employment constant, while fixing prices is trivially equivalent to fixing the real wage. Which of these alternatives is preferable therefore depends on the relative wage elasticities of labor demand $(\phi)$ and labor supply $(\theta) \cdots$ and of course, on the objective governing policy. For the welfare-analytic objective given in (28), for example, the choice between $p=0$ and $x+p=0$ depends on the comparison between

$$
\left.E(\Delta)\right|_{p}=\frac{1}{2}\left[\frac{\phi}{\theta(\phi+\theta)}\right] \phi^{2} \sigma_{z}^{2}
$$

and

$$
\left.E(\Delta)\right|_{\mathbf{X}+\mathbf{p}}=\frac{1}{2}\left[\frac{\phi}{\theta(\phi+\theta)}\right] \theta^{2} \sigma_{z}^{2}
$$

so that the price target is more likely to be preferable if labor demand is the less elastic, while the nominal income target is more likely to be preferable if labor supply is the less elastic.

In fact, no central bank operating in a market economy can simply set efther prices or nominal income exogenously. The feasible analogs to the policies considered in (39) and (40) would therefore consist of evaluating $E(\Delta)$ - or, for that matter, any other specific objective - not for $p=0$ and $x+p$ - 0 but for the respective values of reserves or the interest rate consistent 
with $E_{t-1}\left(p_{t}\right)-0$ and $E_{t-1}\left(x_{t}+p_{t}\right)=0$ for a given information set in general indicating nonzero expectations for the model's disturbance terms. 28

The principal contribution in the literature to date that has investigated either price or nominal income targeting along these lines is Bean's (1983) analysis of nominal income, based on the aggregate supply function given in (14) together with the solved-out aggregate demand relation

$$
x_{t}=\psi\left(m_{t}-p_{t}\right)+e_{t}
$$

where for simplicity "money" is taken as the exogenous policy instrument. 29 As in the analysis above of the demand-only model, the potential role for an intermediate target variable here arises from the assumption of serially correlated disturbances. Specifically, Bean assumed that each of $z$ in (14) and $e$ in (41) consists of the sum of a random walk component and a white-noise component. Bean also posited as the objective governing monetary policy minimizing the variance of real output around the corresponding equilibrium value in the presence of supply shock $z$, which for (14) is just

$$
x_{t}-x_{t}^{e}-\gamma_{1}\left[\left(p_{t}-E_{t-1}\left(p_{t}\right)\right)+\gamma_{2}\left(z_{t}-E_{t-1}\left(z_{t}\right)\right)\right]
$$

Given observations on the model's endogenous variables in period $t-1$, the policy that minimizes $E_{t-1}\left(x_{t}-x_{t}^{e}\right)^{2}$ in the presence of rigid nominal wages is a feedback rule relating $m_{t}$ to the random walk components of $z$ and $e$ in period t-1, but not to the corresponding white noise components. Either fixing the money stock at $m_{t}=0$ without reacting to this information or using nominal income as an intermediate target variable - that is, setting $\mathrm{m}_{t}$ so as to render $E_{t-1}\left(x_{t}+p_{t} \mid m_{t}\right)-0-$ is in general inferior to this optimal feedback policy. 
The resulting variances are

$$
\left.E_{t-1}\left(x_{t} \cdot x_{t}^{e}\right)^{2}\right|_{m}-\Sigma^{2}+\left(\frac{\gamma_{1}}{\gamma_{1}+\psi}\right)^{2}\left[\sigma_{e p}^{2}+\left(\gamma_{2}\left(\gamma_{1}+\psi\right)-\gamma_{3}\right)^{2} \sigma_{z p}^{2}\right]
$$

and

$$
\left.E_{t-1}\left(x_{t}-x_{t}^{e}\right)^{2}\right|_{E_{t-1}(x+p)}-\Sigma^{2}+\left(\frac{\gamma_{1}}{\gamma_{1}+\psi}\right)^{2}\left[\gamma_{2}\left(\gamma_{1}+\psi\right)-\gamma_{3}-\psi+1\right]^{2} \sigma_{z p}^{2}(44)
$$

where $\Sigma^{2}$ is the minimum feasible value of $E_{t-l}\left(x_{t}-x_{t}\right)^{2}$ achieved by the optimal feedback policy, and $\sigma_{\mathrm{ep}}^{2}$ and $\sigma_{\mathrm{zp}}^{2}$ are the one-period variances of the random walk components of the disturbances to aggregate demand and aggregate supply, respectively. 30

The $m$ - $O$ policy is inferior to the optimal feedback rule, therefore, in that it always fails to take proper account of what is known about the demand disturbance, and except when $\psi=1$ it also fails to take proper account of the supply disturbance. Similarly, although the policy of setting $E_{t-1}\left(x_{t}+p_{t}\right)-0$ does eliminate the effect of the predictable component of the demand disturbance, it too is inferior to the optimal feedback policy in that it fails to take proper account of the supply disturbance (except trivially when $\phi_{2}-1$. which from (15) implies an inelastic labor supply, so that supply disturbances do not affect the equilibrium output level in the first place). Hence the choice between these two sub-optimal policies rests on the comparison between (43) and (44). Because a sufficient condition for the variance in (44) to be less than that in (43) is $\phi<1$, and indeed the available empirical evidence suggest a less-than-unit elasticity of real aggregate demand with respect to 
real balances, Bean concluded that monetary policy based on nominal income as an intermediate target is likely to be preferable to a policy based on exogenously fixing "money." 31

West (1986), however, showed that this apparently straightforward conclusion hinges crucial-y on the choice of minimizing $E_{t-1}\left(x_{t}^{2}\right)$ as the objective governing monetary policy. As an example, West showed that when minimizing $E_{t-1}\left(x_{t}^{2}\right)$ is the policy objective, the conclusion in a highly similar model is just the opposite. In that case a nominal income target is preferable to a fixed money stock if and only if the elasticity of aggregate demand with respect to real balances is greater than unity. ${ }^{32}$ The main point here, therefore, is not just the inherently empirical nature of the key choices involved in designing monetary policy but also, in a model encompassing both supply and demand, the importance of the choice of policy objective.

A further generalization of the idea of using either a price or a nominal income target for monetary policy is Hall's (1984) analysis of an "elastic" price target, whereby the central bank sets its policy instrument so as to achieve

$$
E_{t-1}\left(P_{t}\right)-\xi U_{t}
$$

where $U$ is the difference between the actual unemployment rate and the corresponding "full employment" benchmark, and the base from which the percentage price deviation $p$ is measured (here normalized to zero, as usual) is specifically intended to be constant over time. When the targeting rule's elasticity $\xi$ equals the reciprocal of the elasticity relating unemployment to real income - - that is the "Okun's Law" coefficient (usually estimated empirically to be around one-third for the United States) - - this elastic price 
standard is equivalent to nominal income targeting. A larger value of $\xi$ places relatively greater implicit weight on unemployment (real output), while a smaller value places relatively greater implicit weight on the price level. Instead of making explicit the objective implied by (45) and working out analytically the relevant variances that follow from implementing it under some specific model, Hall performed simulations based on empirical estimates of the time series of the respective disturbances to aggregate demand and aggregate supply for the United States, and on an assumed value (one-half) for the elasticity of the supply curve relating price setting to the level of unemployment.

In a similar vein, Taylor (1985) used simulations of a bivariate autoregressive process generating prices and real income, estimated using U.S. time series data, to evaluate several different versions of a nominal income targeting procedure. Taylor also explicitly considered, but did not simulate, a generalization of this procedure analogous to Hall's elastic price standard. In their reliance on empirical simulations rather than analytical solutions, both Taylor's and Hall's analyses are in the spirlt of the earlier empirical work evaluating alternative monetary policy rules on the basis of simulations of large econometric models. ${ }^{33}$ Nevertheless, generalization of the use of prices or nominal income as an intermediate target variable to a rule like (45), with its readily intuitive constant-elasticity form, is easily compatible with the more explicitly analytical line of development of this literature in recent years.

The Information Variable Approach

The repeated analytical demonstration of the inferiority of using some endogenous variable as an intermediate target of monetary policy, compared to a 
more general feedback rule optimally relating the value of the policy instrument to the observed value of that variable, has shaped the subsequent monetary policy literature in recognizable ways. It was readily apparent in work like that of Friedman (1975) and Bean (1983) that the optimal feedback rule which dominates the intermediate target strategy is a vehicle for exploiting the information contained in observations of the endogenous variable in question. Under such a rule, the endogenous variable is not an intermediate target but an "information variable" in the sense earlier made explicit in a monetary policy setting by Kareken et al. (1973).

The basic idea at work in the information variable approach is again dynamic, arising in just the context discussed above, of either behavioral lags or economic lags discussed above as the motivation for the intermediate target strategy. Observations of a variable like the money stock are potentially useful for anticipating future stochastic movements of variables like income and prices that enter the central bank's objective, or for estimating contemporaneous stochastic movements of these variables before the relevant direct data became available. In either case, feedback rules like those derived by Friedman and Bean constitute the optimal way of exploiting that information, given the assumed behavioral model and policy objective. ${ }^{34}$

One implication of this "information variable" approach is that issues of behavioral causation, which had dominated much of the earlier discussion, became secondary. 35 Whether the money stock does or does not "cause" movements of future income or prices is not the issue here. All that matters is whether observed values of the money stock provide information that helps predict future movements of these variables. Hence statistical analyses along the lines of Granger (1969) and Sims (1972) are apt, despite questions about whether such tests are capable of saying anything about economic causation. 36 In addition, 
Friedman (1984b) showed that tests of whether or not money provides such information can also be performed within a structural model context.

Another implication of the conceptual shift from an intermediate target approach to an information variable context is that there is no longer any compelling reason to limit the focus of the central bank's policy setting rule to only one such endogenous variable. In principle, of course, it is always possible to employ some appropriately weighted combination of two or more endogenous variables is an intermediate target. In practice, however, the intermediate targets proposed in the literature have almost always been univariate or, like nominal income, an unweighted combination usually regarded as a single variable anyway. 37 By contrast, under an information variable approach there is no reason to restrict monetary policy to respond only to one endogneous variable, unless there is evidence suggesting that observations of that one variable contain all (or nearly all) of the available information relevant to achieving the central bank's objectives. Instead, it is in general optimal to follow the approach, intuitively outlined earlier on by Guttentag (1965), of exploiting all relevant sources of information.

Friedman (1982a, 1983) explored along these lines the implications of basing monetary policy on both a money stock variable and a credit variable, on the basis of empirical evidence for the United States showing not only that credit (defined as the outstanding indebtedness of all U.S. obligors other than financial intermediaries) contains approximately as much information about subsequent movements of income and prices as does any conventional measure of money, but also that the interaction between the effects of credit and the narrow (M1) money stock is such that both variables together provide significantly more information in this context than does either taken alone. At an intuitive level, the principal argument here is that using a credit variable 
in this way diversifies the information base underlying monetary policy responses to observations of ongoing events, in that credit describes the liability side of the nonbank public's balance sheet while measures of money describe the asset side. Subsequent contributions by other researchers investigated further the potential role of a credit variable in guiding monetary policy, relying either on empirical evidence on the relationship of credit to macroeconomic variables or on theoretical arguments, along the lines of Blinder and Stiglitz (1983) or Bernanke and Gertler (1986). In addition, Modigliani and Papadernos (1983) developed a theoretical argument relating the relative usefulness of money and credit variables in this context to issues of financial market structure.

Like the optimal feedback rules derived in the various models considered above, the information variable approach to monetary policy - - whether based on one information variable, or two, or many - makes explicit the need for a clearly articulated objective to govern policy, as well as a model stating the relationship between the variable(s) comprising that objective and the central bank's policy instrument. Given these basic tools, the question of what further role additional endogenous variables can play in the policy process is largely an empirical issue of what (if any) readily observable financial prices or . quantities contain potentially useful information to guide the setting of the policy instrument in order best to achieve the objective. ${ }^{38}$ At the same time, the optimal choice of policy instrument is not independent of the potential use of information variables in this way. Which instrument delivers the smallest variance for a given objective in a given model depends in general on the appropriately conditioned variances of the principal stochastic disturbances affecting economic behavior, and variances conditional on different information sets are not the same. 
II Implementing Monetary Targets: The Instrument Problem Once Again Notwithstanding the analytical shortcomings of monetary (or other) intermediate targets as a basis for monetary policy, beginning in the 1970s, central banks in an increasing number of countries adopted - or at least professed to adopt - monetary aggregate targets. Given the endogeneity of the quantities that most of these central banks meant by "money," the issue of how best to achieve these targets became a logical next step in the development of the targets and instruments literature, indeed a step that antedated either the attention to supply shocks or the formal analysis of the intermediate target strategy emphasized in Section II.

The separate literature of controlling monetary aggregates made clear the fundamentally two-stage character of the monetary policy process based on an intermediate target variable. Here the existence of a specified target value for the money stock, presumably determined via some prior analysis involving macroeconomic variables of genuine policy consequence, is simply a given. The remaining question is how the central bank is to set its exogenous policy intrument so as to render the actual value of the money stock as close as possible to this target value, in the context of different stochastic disturbances affecting money supply and money demand. The fact that the realizations of these disturbances will in general affect the value of the money stock that is consistent with achieving the underlying macroeconomic objectives of this policy -. which is, in the end, the basic analytical flaw in the intermediate target strategy itself .- went unconsidered here.

\section{Analysis Under Fixed Institutional Arrangements}

Pierce and Thomson (1972) first explicitly framed the money stock control problem in a conceptional framework analogous to Poole's (1970), also using a 
demand-only model like Poole's. More specifically, they examined whether nonborrowed reserves or a short-term interest rate is the superior policy instrument for minimizing the variance of the money stock around some given target value when money is determined by the interaction of the money demand and supply functions (2) and (31), with income taken as pre-determined but not known with certainty in advance. The alternative solutions to this problem are

$$
\begin{aligned}
&\left.E\left(\mathrm{~m}^{2}\right)\right|_{\mathrm{r}}=\sigma_{\mathrm{v}}^{2}+\beta_{1}^{2} \sigma_{\mathrm{y}}^{2}+2 \beta_{1} \sigma_{\mathrm{vy}} \\
&\left.\mathrm{E}\left(\mathrm{m}^{2}\right)\right|_{\mathrm{h}}-\frac{1}{\left(\beta_{2}+\delta_{2}\right)^{2}}\left[\delta_{2}^{2} \sigma_{\mathrm{v}}^{2}+\beta_{2}^{2} \sigma_{\mathrm{q}}^{2}+\beta_{1} \delta_{2}\right)^{2} \sigma_{\mathrm{y}}^{2} \\
&\left.-2 \delta_{2} \beta_{2} \sigma_{\mathrm{vq}}+2 \beta_{1} \delta_{2}^{2} \sigma_{\mathrm{vy}}-2 \beta_{1} \beta_{2} \delta_{2} \sigma_{\mathrm{qy}}\right]
\end{aligned}
$$

where $\sigma_{y}^{2}$ is the variance of the forecasting error associated with $y$ (and covariances $\sigma_{v y}$ and $\sigma_{q y}$ are defined analogously).

The result here is parallel to those derived above. Which policy instrument minimizes $\mathrm{E}\left(\mathrm{m}^{2}\right)$ depends upon the relative magnitudes of the three relevant variances (and the covariances), and on the respective elasticities describing the nonbank public's money demand behavior and the banking system's money supply behavior. The interest rate instrument exposes the money stock to money demand disturbances and to effects on money demand due to unexpected movements in income, both on a one-for-one basis, but entirely shields the money stock from money supply disturbances. The reserves instrument damps money demand disturbances and the effects of unexpected income variation, both with damping factor $0<\frac{\delta_{2}^{2}}{\beta_{2}^{2}+\delta_{2}^{2}}<1$, but exposes the money stock to money supply 
disturbances. Which instrument is superior under these assumptions is an empirical matter. 39

McCallum and Hoehn (1983) carried out an analogous investigation in the context of the supply-demand model consisting of (8)-(10) and (31). 40 Here the alternative solutions are (apart from covariance terms)

$$
\left.E\left(m_{t}^{2}\right)\right|_{r}-\sigma_{v}^{2}+\left(\frac{1+\beta_{1} \gamma_{1}}{\alpha_{1}+\gamma_{1}}\right)^{2} \sigma_{u}^{2}+\left(\frac{\alpha_{1} \beta_{1}-1}{\alpha_{1}+\gamma_{1}}\right)^{2} \sigma_{2}^{2}
$$

and

$$
\left.E\left(m_{t}^{2}\right)\right|_{h}-\frac{1}{(1+\psi)^{2}}\left[\sigma_{v}^{2}+\left(\frac{1+\beta_{1} \gamma_{1}}{a_{1}+\gamma_{1}}\right)^{2} \sigma_{u}^{2}+\left(\frac{\alpha_{1} \beta_{1}-1}{\alpha_{1}+\gamma_{1}}\right)^{2} \sigma_{z}^{2}+\psi^{2} \sigma_{q}^{2}\right]
$$

where $\psi=\frac{1}{\delta_{2}}\left[\alpha_{1}\left(\frac{1+\beta_{1} \gamma_{1}}{\alpha_{1}+\beta_{1}}\right)+\beta_{2}\right]$. As usual, the interest rate instrument exposes the money stock to disturbances to money demand behavior on a one-for-one basis, and to disturbances to real spending and to aggregate supply ighted by the relevant elasticities. The reserves policy damps the effect on money due to all three of these disturbances, with damping factor $0<\frac{1}{(1+\psi)^{2}}<$ 1, but exposes the money stock to disturbances to money supply behavior. Which instrument is superior is again an empirical question.

\section{Analysis of Alternative Institutional Arrangements}

Although it is possible to think of numerous changes in the institutional structure of a country's financial markets that might affect its central bank's ability to achieve the objectives motivating monetary policy, the monetary economics literature has not taken up such suggestions in any systematic way. 41 
By contrast, suggestions for changing institutional arrangements so as to improve the efficacy of the central bank's control over the money stock have attracted substantial attention.

Given the fractional reserve system underlying the money supply process in nearly all market economies, the chief focus of this attention has been the structure of reserve requirements. Davis (1971) early on catalogued many of the familiar slippages in the control of monetary aggregates via open market operations, and Poole and Lieberman (1972) subsequently elaborated the potential importance in the U.S. context of more uniform reserve requirements, both across different forms of monetary liabilities and across different categories of money-issuing institutions. Especially in the context of the large realized month-to-month (and even quarter-to-quarter) variations in U.S. money growth during the 1979-82 period, during which the Federal Reserve System publicly maintained that controlling money growth was its chief operating priority, the specific aspect of this subject that attracted the most attention was the presence of a time $\mathrm{lag}$ in the requirement that banks hold reserves based on their deposits.

McCallum and Hoehn (1983) analyzed the implications of lagged reserve requirements in the context of the supply-demand model consisting of ( 8$)-(10)$, as immediately above, and instead of (31) a reserves demand relationship given by

$$
m_{t-1}=\delta_{1} h_{t}+\delta_{2} r_{t}+q_{t}
$$

Because the money-supply/reserves-demand equation does not affect the determination of the money stock anyway when the exogenous monetary policy instrument is the interest rate, the substitution of (50) for (31) leaves 
$\left.E\left(m_{t}^{2}\right)\right|_{r}$ in (48) unchanged. By contrast, under lagged reserve requirements the corresponding variance when the stock of reserves is the policy instrument is

$$
\left.E\left(m_{t}^{2}\right)\right|_{h}=\sigma_{v}^{2}+\left(\frac{1+\beta_{1} \gamma_{1}}{a_{1}+\gamma_{1}}\right)^{2} \sigma_{u}^{2}+\left(\frac{a_{1} \beta_{1}-1}{a_{1}+\gamma_{1}}\right)^{2} \sigma_{z}^{2}+\psi^{2} \sigma_{q}^{2}
$$

Because the exogenous reserves policy in this context is equivalent to the exogenous interest rate policy except for the addition of some slippage $\left(\sigma_{\mathrm{q}}^{2}\right)$ in setting the interest rate, it is clearly inferior in that it provides no damping of the three disturbance terms in (48) but merely adds a fourth.

Under a system of lagged reserve requirements, therefore, the interest rate unambiguously dominates the stock of reserves as the policy instrument for controlling the money stock. 42 Despite the unusual (for this literature) emergence of a result that is not inherently empirical, the subsequent literature on this issue has nonetheless largely focused on empirical questions like how large the increase in variance from (49) to (51) really is, especially in more fully specified and disaggregated models of money supply and demand, and to what extent the use of the reserve demand relation (50) together with macroeconomic relations like $(8)-(10)$ is consistent with the typically very short time delay involved in most actual lagged reserve systems. 43

Apart from the timing, coverage and uniformity of reserve requirements, the principal issues of institutional arrangements discussed in the literature of controlling money as an intermediate policy target have been the central bank's discount window procedure for lending reserves to banks, responses to technical factors like variations in float and currency in circulation, problems of timeliness and accuracy of data, and the ever-present problem of seasonal adjustment. Poole and Lleberman's (1972) early review of the subject 
encompassed most of these issues, and more recently Levin and Meek (1981), Santomero (1983), Goodfriend (1983) and others have focused in particular on the role of discount window borrowing.

\section{Problems of Volatility and Instability}

Another set of issues that arises when the central bank uses some measure of money as an intermediate target, especially in the context of reserves as the exogenous policy instrument, is the prospect of excessive volatility of interest rates. In simple models like those analyzed above, there is no apparent reason why interest rate volatility should be a policy concern. In fact, however, most central banks have historically sought to minimize interest rate volatility, and it is not difficult to posit richer models of income determination in which interest rate volatility can matter. 44

In a one-period context, interest rate volatility simply means the variance of the interest rate - or, more generally, of the entire constellation of interest rates - a around the corresponding expected value(s). Here the connection to the choice of policy instrument is clear enough. Under an interest rate instrument, whatever interest rate the central bank sets exogenously has zero variance in this sense. Under a reserves instrument, the variance is nonzero. In the model consisting of (8)-(10) and (31), for example, the one-period variance of $r$ when $h$ is exogenous in general incorporates the respective variances (and covariances) for each of $u, v, z$ and $q$. Under most familiar theories of asset pricing, this larger one-period variance for a specified short-term interest rate implies larger one-period variances for other interest rates as well.

In a dynamic context, the question is both richer and more subtle. Here the issue is not just the within-period variance of any interest rate around its 
expected value but the movements of interest rates from one time period to the next, including whatever deterministic component renders each period's expected value not the same as the prior period's realization. Although the literature has typically been vague at best in distinguishing these two senses of interest rate volatility, central banks have typically exhibited concern for both.

Within the research literature, the empirical work of Tinsley et al. (1981) has been an exception in focusing explicitly on interest rate volatility in both senses. Whether interest rate volatility in this second, dynamic sense is likely to be greater under an interest rate instrument or some other policy strategy is not clear a priori. Using a reserves instrument, or using money as an intermediate target, exposes each period's interest rate to a variety of shocks as in the models analyzed above. By contrast, if use of an interest rate instrument leads to increased variation in price inflation, and if realized inflation affects the central bank's subsequent setting of the interest rate -. as is the case, for example, if the inflation rate exhibits inertia, and the interest rate that matters for economic activity is the real interest rate -. then the period-to-period variance of (nominal) interest rates may be greater under an interest rate instrument. More generally, any monetary policy system that results in a volatile inflation rate is likely to increase the period-to-period volatility of nominal interest rates.

Finally, in a dynamic context the extent of period-to-period interest rate volatility also depends on the objective specifying how rapidly the central bank seeks to restore income (or prices, or money) to the corresponding targeted path, once a departure from that path has occurred. The point at issue here is a straightforward application of Holbrook's (1972) analysis of the problem of instrument instability, which can arise whenever the effects of policy instruments on policy targets are distributed through time. Ciccolo (1974), 
Enzler and Johnson (1981), Freedman (1983) and others have analyzed the potential instability that can result from excessively close control of a money target, given the extensive evidence indicating that money demand behavior exhibits a lagged response to interest rates. ${ }^{45}$ The point is presumably applicable in a broader context as well, given the even more substantial evidence documenting lags in the response of nonfinancial behavior to movements in financial prices and quantities. 


\section{Other Issues}

In addition to the central analytical issues revlewed in Sections I, II and III, the literature of targets and instruments of monetary policy has also encompassed a variety of specific related questions. The most prominent among these include the implications of the central bank's operating procedures for the behavior of the private sector, positive questions about whether central banks did or did not in fact use a particular operating procedures during a particular time period (a question often taken up in the context of a central bank's own public assertion that it did so), and the voluminous empirical literature examining which financial quantities best display the properties appropriate for a monetary policy target.

\section{Monetatary Policy and Private Information}

A central theme running throughout the targets and instruments literature, and especially in the analysis of the intermediate target problem as laid out in Section II, is the central bank's exploitation of available information. At the ame time, however, it should be clear that the structure of the policy process - what potential instrument variable is exogenous, what (if any) intermediate target variable provides the basis for automatic responses of the instrument, and so on -. also affects the information available to the economy's private sector. To the extent that that is so, holding private-sector behavior fixed for purposes of analysis like that above is potentially misleading. 46 Dotsey and King (1986), building on King's (1982, 1983) earlier work, reconsidered Poole's (1970) original evaluation of interest rate versus money stock instruments in the context of a model in which private-sector decision makers learn from observing market prices, including nominal interest rates, and in which inadequacies of information afe by assumption the only impediment to 
achieving the equilibrium level of output. 47 Their analysis shows that an interest rate target rule, by which the central bank uses a feedback rule to set $E_{t-1}\left(r_{t}\right)$ on the basis of observed economic outcomes in period $t-1$, but then allows disturbances to the economy to affect the corresponding actual realization $r_{t}$, is equivalent to a feedback rule similarly relating the value of the money stock to observed economic outcomes. Dotsey and King also showed that in their model either of these feedback rules in general dominates either a fixed interest rate policy or a fixed money stock policy, so that the analogy to Poole's original result is even more complete.

Siegel (1985) used a much simpler model, again incorporating flexible prices, to consider what properties make a monetary aggregate a useful "indicator" of unobservable variables like income and prices. As in Dotsey and King's work, but in contrast to the line of analysis in Sections I-III, the presumption is that with full information the private economy on its own will operate at equilibrium, so that the purpose of variables that provide information is to facilitate this private-sector process rather than to enable the central bank to assist the private sector in reaching equilibrium. Siegel showed that monetary assets with demands that are not income elastic in general provide the most information about both prices and real income, while monetary assets with demands that are highly income elastic provide the most information about nominal income. Siegel also emphasized the more familiar point that monetary assets that are extremely closely related to the reserve base provide little information about any endogenous variables when the central bank uses reserves as its exogenous policy instrument. Both of these conclusions are especially relevant in the context of the empirical literature discussed below. Moreover, Siegel's conclusions are also favorable to simultaneously using more than one aggregate as information variables, along the lines discussed in 
Section II.

\section{What the Central Bank Did or Didn't Do}

The adoption of at least some form of monetary target for monetary policy became widespread during the 1970s - at least according to what central banks said about their own policies. By contrast, economists and other observers of monetary policy (both official and private) have often expressed doubts that some central banks' adoption of such targets was more than rhetorical. Most often, skepticism of this kind has ensued when an announced policy based on a monetary aggregate target did not deliver the results previously claimed in behalf of such a policy by its advocates. A logical question in that case is whether the policy was unsuccessful or, alternatively, was simply never tried. This issue became especially lively in the United States in the wake of the emphasis on monetary aggregate targets which the Federal Reserve System officially said it adopted in 1979 and abandoned in 1982.48

An early contribution along these lines was DeRosa and Stern's (1977) effort to establish whether the Federal Reserve System had adopted (at least in part) a monetary aggregate target in 1970. Their analysis, which largely set the pattern for future efforts along these line, involved empirically estimating a central bank reaction function of the form

$$
\Delta r_{t}=f\left(\Delta M_{t-1}-\Delta M_{t-1}^{*}, \underline{x}_{t-1}\right)
$$

where $\Delta r$ is the change in the interest rate used as the exogenous policy instrument, $\Delta M$ is the growth rate of whatever monetary aggregate is in question as the supposed intermediate policy target, $\Delta M^{*}$ is the corresponding announced target value, and $\underline{x}$ is a vector of other variables (like price inflation or 
unemployment) to which monetary policy may plausibly respond. ${ }^{49}$ Addressing the question of the adoption of a monetary target as of a specific date then amounts to testing for a change in the reaction function coefficients, in particular the coefficient on the $(\Delta M-\Delta M *)$ term, at that point in the data sample. DeRosa and stern reported statistically significant evidence of such a change for the United States in 1970.

The subsequent literature has evolved along roughly the same lines. Prominent examples for the U.S. case are tests by Feige and McGee (1979) and by Lombra and Moran (1980) for Federal Reserve behavior following the 1975 adoption of a Congression resolution calling for monetary aggregate targets, and by Hoehn (1983) for Federal Reserve behavior during the controversial 1979-82 period. In each case, the evidence again indicated a statistically significant change at the time indicated.

As Lombra and Moran emphasized, however, statistical significance and economic significance are not always the same. In their results, for example, the post-1975 response of the federal funds rate to observed deviations of money growth from the corresponding target value was statistically significant, but so small (compared to the benchmark provided by empirical estimates of the interest elasticity of money demand) as to cast doubt on how large a role the monetary target actually played in the Federal Reserve System's decisions setting interest rates. This point has featured prominently in the subsequent literature, especially since empirical estimates almost always indicate a very small (in absolute value) interest elasticity of money demand in the short run, so that a correspondingly large response of interest rates to observed movements in the money stock would be necessary to correct such movements within any short time frame. 


\section{Evidence Comparing Alternative Target Variables}

One of the most troublesome contrasts between the world described by simple models like those surveyed throughout this paper and the world in which actual central banks make monetary policy is the multiplicity (in the latter) of different deposit instruments, and hence the multiplicity of different monetary aggregates. Before it can take advantage of the insights of a typical model including a single variable labeled " $M$ " and called "money," therefore, a central bank operating in any well developed financial system must decide just which variable "M" is. Moreover, the experience of many countries has now cast strong doubt on the proposition, sometimes offered as a way of minimizing the importance of this choice, to the effect that all of the potential "M's" typically move together anyway. That may be so in the context of a hyperinflation, but in countries experiencing ordinary business fluctuations under moderate inflation different " $M$ ' $S$ " often display widely disparate growth rates, even for periods of several years at a time. Hence even saying whether monetary policy is tight or easy, or has tightened or eased, often depends crucially on which deposit aggregate is construed as "money."

The approach that the literature has taken to this question is primarily empirical, and the resulting body of available empirical research is both large and extensive, covering different time periods and different countries and employing a variety of statistical methodologies. Although it is not the purpose of this paper to survey this empirical literature in any detail, it is us.. $: 1$ nonetheless to indicate how its main strands relate to the analytical issues discussed in Sections I-III. 50

By far the greatest part of this empirical research, and the part with the longest history, has investigated the connection between alternative financial aggregates and macroeconomic variables plausibly construed as defining the 
ultimate objectives of monetary policy. The earlier efforts along these lines primarily employed the statistical methodology that grew out of the work of Friedman and Meiselman (1963) and Andersen and Jordan (1968). The question usually asked in this line of research is which aggregate delivers the best "fit" when employed as $M$ in equations of the form

$$
\Delta Y_{t}=f\left(\sum_{i=1}^{n} \omega_{i} \Delta M_{t-1}, x_{t-1}\right)
$$

where $\Delta Y$ is the growth rate of nominal income, $\Delta M$ is the growth rate of the aggregate, $X$ is a vector of other variables affecting $\Delta Y$ (frequently used elements of $X$ include a fiscal policy measure and a dummy variable indicating major labor union strikes), and the $\omega_{i}$ are a set of distributed lag weights to be estimated. Following the work of Granger (1969) and Sims (1972), however. the question more typically asked has become not just whether some $M$ can predict the future variation of $Y$ but, more specifically, whether $M$ can predict that part of the variation in $\mathrm{Y}$ not already predictable from the observed movement of $\mathrm{Y}$ itself. This subsequent line of research has therefore relied on equations of the form

$$
\Delta Y_{t}=f\left(\sum_{i=1}^{n} \omega_{i} \Delta M_{t-i}, \sum_{i=1}^{n} \phi_{i} \Delta Y_{t-i}\right)
$$

where the $\phi_{1}$ are distributed lag coefficients analogous to the $\omega_{i}$. Empirical research along the lines of either (53) or (54) bears a fairly direct relation to the analytical issues under discussion in Sections I-III. In either case, the object is to find the aggregate that, if employed by the central bank as its intermediate target variable in the case of deposit or loan 
aggregates that are necessarily endogenous, or if employed as the exogenous policy instrument in the case of aggregates like nonborrowed reserves or the monetary base, would deliver a smaller variance of income about its expected value. Further, the recognition that nominal income may be less relevant than real income and prices separately in defining the ultimate objective of monetary policy has often led to trivariate (and sometimes higher-order) generalizations of (54), with separate equations for real income and prices, respectively.

An even more traditional line of empirical work that some researchers have also brought to bear on the selection of an aggregate for monetary policy purposes is the estimation of money demand functions. Here the connection to the analytical issues considered in Sections I-III is even more straightforward. While equations like (53) or (54) at best represent reduced-form solutions to the models that typically underlie the analytical side of this literature, empirical money demand functions are, in principle, direct implementations of equations like (9) which are clearly central to the analysis. Consequently, empirical estimation of money demand functions can provide values of such rrucial behavioral parameters as elasticities $\beta_{1}$ and $\beta_{2}$ and variance $\sigma_{\mathrm{v}}^{2}$ in $(9)$. Especially in the wake of the trend toward deregulation and private innovation in the financial markets of many countries, the literature of empirically estimated money demand functions has grown enormously in recent years. 51

There has also been a substantial amount of empirical research focusing on the relationship between alternative monetary aggregates and variables that comprise potential exogenous instruments of monetary policy. Here what is at issue is the monetary control problem, as outlined in Section III, and the connection to the underlying analytical issues is typically both direct and explicit. Much of the work along these lines has exploited empirical models of money demand and money supply to estimate the variance that would be associated 
with the use of a specific instrument variable (for example, nonborrowed reserves or the federal funds rate) to affect a given endogenous monetary aggregate used as an intermediate target variable. ${ }^{52}$ An alternative approach, employed by Johannes and Rasche (1979), is to use time-series methods to estimate what amounts to a reduced-form equivalent of such models.

Two specific aspects common to all three of these lines of empirical research bear explicit comment as they relate to the literature of targets and instruments of monetary policy. First, whether or not "money" exhibits properties that bear implications for choosing a particular monetary policy framework is increasingly not an independently testable question, at least on the basis of historical data, because central banks can and do use the results of statistical studies like those described above as a basis for deciding how to define "money" in the first place. 53 Second, a striking feature of this entire field of empirical investigation is the remarkable extent to which researchers who otherwise profess strong sympathy with Lucas' (1976) criticism of the use of econometric models for policy purposes, on the ground that a change in policy procedures will in general induce a change in economic behavior and will therefore invalidate the model, have simply ignored this criticism as it applies to these kinds of exercises as a basis for selecting the best " $M$ ". 


\section{Some Broader Is sues}

In conclusion it is also useful to consider briefly the relationship between the main line of analytical issues developed in the targets and instruments literature and some other broad issues involved in the conduct of monetary policy. The most obviously relevant among these are the traditional issues of rules versus discretion, and of activism versus nonresponsiveness, in the making of economic policy more genearally. 54

In a single-period context, the entire subject of targets and instruments of monetary policy falls squarely into the general discussion of rules for guiding policy. In this sense the choice of an exogenous policy instrument, and in some cases also of an intermediate policy target, amounts to picking a rule for determining how the economic system -- here including the actions of the central bank - - will translate the various disturbances to which the economy is subject into effects on its overall performance. Some of these implied rules are simple. Others, including feedback rules of the kind derived in Section II, are more complicated. In the end, however, within the context of a single Deriod each is a rule nonetheless.

Following the work of Kydland and Prescott (1977) and Barro and Gordon (1983), however, the modern literature of rules versus discretion is mostly about what happens in a dynamic context, and here the connection to the targets and instruments literature is less straightforward. Is the central bank presumed to make the same choice of instrument variable (and intermediate target variable, if any) in each period? What aspects of the economy's condition inherited from the previous period does it take into account in defining the objective which motivates its actions in each period? What kind of feedback rules does it employ in relating the value of its instrument (and its intermediate target, if any) to those conditions? In what way does its 
objective take account of the implications of its current actions for future time periods? The relationship between the issues reviewed in Sections I-III and the rules versus discretion debate hinges importantly on the answers to questions like these.

One line of thinking that implicitly addresses many of these questions, clearly articulated by Tobin (1983), for example, is that in the world of actual policymaking "rules" necessarily mean simple rules. In that case the analytical issues reviewed in this paper do bear quite directly on the rules versus discretion debate, since the typical outcome of the line of analysis surveyed here is to demonstrate the inferiority in general of simple rules - $f$ ix the reserve base, $f i x$ an interest rate, fix the expected value of the money stock, and so on - - compared to rules specifying responses that take account of at least some of the available information about the disturbances affecting economic behavior. If rules must be simple ones, therefore, the targets and instruments literature not only demonstrates the qualitative inferiority of rules but provides guidelines for quantifying that inferiority. Nevertheless, the issue remains open, not only because of questions about the empirical magnitudes involved but also because others who have thought about these issues - for example, McCallum (1985) - r reject the view that rules must be simple in order to be practically relevant.

The literature of targets and instruments of monetary policy is also closely related to the issue of activism versus nonresponsiveness.

Nonresponsiveness essentially means a simple rule - fix this, or fix that - while activism means responding to initial conditions, or to evidence of disturbances, according to one feedback rule or another. Even so, because the nonresponsive rules that have attracted the most attention over the years have typically referred to some endogenous variable like money, rather than to some 
variable that the central bank can set directly (like nonborrowed reserves), in the end the real question is not whether or not to respond to anything at all but rather which classes of phenomena merit a response and which do not. This kind of question is clearly at the analytical heart of the targets and instruments literature surveyed in Sections I-III.

Framing the issue in this way also makes clear the limited applicability of Friedman's (1953) classic criticism of activist policy on the ground that varying policy from the no-response, or base, position in general introduces uncertainty, and with sufficient ignorance may introduce sufficient uncertainty to increase the variance of the policy objective rather than reduce it. The targets and instruments literature brings to center attention the problem of defining the base position in the first place in a stochastic environment. Does it refer to an interest rate, to the reserve base, or to money? Does it refer to levels or to changes of whatever variable is at issue?

Analysis along the lines of the targets and instruments literature indicates how to answer such questions on the basis of any given model, and typically any given model will imply that in general at least some degree of responsiveness dominates a purely nonresponsive policy, even after allowing for uncertainty surrounding the model's coefficients as illustrated by Brainard (1967). Although many economists have argued as if an even deeper level of uncertainty - - in particular, ignorance about what is the right mode l - somehow implies that fixing some measure of money constitutes the appropriate definition of the base position for purposes of this issue, there is no obvious reason to accept this presumption. In the absence of at least some articulated model indicating the likely implications of the central bank's policy actions for its policy objectives, no conclusions of this kind are possible at all. There is no more reason for presuming that qualitative propositions about "money" uniquely 
survive the absence of a model than for the presumption that empirical evidence involving "money" uniquely survives Lucas" (1976) point about public policy and private behavior.

Finally, although it is easy enough as a matter of abstract analysis to discuss all of these aspects of monetary policy as if "policy" and "politics" did not have the same root, political considerations are hardly irrelevant to the issues involved in the targets and instruments literature. A frequently expressed motivation underlying the intermediate target strategy -- articulated by Poole (1980), for example .. is to provide a mechanism enabling higher governmental authorities as well as the general public to hold the central bank politically accountable for its conduct of monetary policy. Whether this argument is compelling must in the end depend both upon the quantitative degree of inferiority of the intermediate target strategy compared to a given alternative, determined along the lines analyzed here, and on the risks and consequences associated with the relevant central bank decision makers may do in the absence of such an accountability mechanism. That these risks and consequences are difficult to specify does not necessarily make them less real. At least thus far, however, this difficulty has largely prevented the development of any substantial body of monetary policy research incorporating. them. 


\section{Footnotes}

*This paper was prepared for the Handbook of Monetary Economics (B.M.

Friedman and F. Hahn, eds.), North-Holland Publishing Company, forthcoming. I am grateful to Alan Viard for research assistance, and to the National Science Foundation and the Harvard Program for Financial Research for research support.

1. See the treatment of rules versus discretion in Stanley Fischer's contribution to this Handbook.

2. See, for example, the useful surveys by Cagan (1982) and McCallum (1985), and the more recent references cited in Friedman and Kuttner (1988).

3. See the treatment of monetary policy in open economies in Rudiger Dornbusch and Alberto Giovannini's contribution to this Handbook.

4. Throughout the remainder of this paper, "banks" will be taken to include all financial intermediaries making loans and taking deposits subject to reserve requirements set by the central bank or a parallel regulatory body.

5. In some countries, direct lending of reserves - the "discount window" -. is also of substantial importance. More typically, however, variations in discount policy are considered significant largely to the extent that they are signals of intended future open market operations. See Lombra and Torto (1977) for evidence pertinent to the U.S. case.

6. See, for example, Cagan's (1978) review of the billionist controversy in England in the nineteenth century, and Friedman and Schwartz's (1963) 
$-61-$

account of the debate over gold (or bimetallic) standards in the United States.

7. This idea was familiar in a less formal way earlier on, however. For example, the debate between Frledman and Meiselman (1963, 1965) and Ando and Modigliani (1965a, 1965b), over the relative stability of the money-income and investment-multiplier relations, was clearly in part about the usefulness of money as a target of monetary policy, although neither side expressed the issues in Poole's terms of IS and LM curve variances. See also Brunner and Meltzer $(1964,1967,1969)$ and the papers in Federal Reserve Bank of Boston (1969) for key pre-1970 contributions.

8. These conventions of notation - all constants set to zero, lower-case variables in logarithmic form and interpreted as deviations from equilibrium values, all coefficients non-negative - will be maintained throughout the paper.

9. If $\sigma_{u}^{2}-\sigma_{v}^{2}-0$, the problem is trivial and either instrument implies $E\left(y^{2}\right)=0$.

10. See Tobin (1983) for a useful intultive discussion along these lines.

11. For examples of applications to these specific contexts see Aizenmann and Frenkel (1985), Gray (1976) and Fischer (1977b).

12. Sargent and Wallace also demonstrated that under rational expectations the real interest rate $\left[r_{t}-\left(E_{t-1}\left(p_{t+1}\right)-p_{t}\right)\right]$ is invariant with respect to such 
choice of $m_{t}$.

13. Standard references on this subject include Modigliani (1963) and Patinkin (1965). Although the more recent literature has focused on explicit (and analytically tractable) rigidities like contracts specifying fixed nominal wages, it is more plausible to regard wage and price rigidities of a more implicit nature as pervasive throughout the economy; see, for example, Fischer (1980).

14. To recall, all constants are suppressed, so that (21) gives equilibrium values stated as percentage deviations around the corresponding deterministic values that would obtain with $z=0$.

15. Alternatively, if the zero-mean property of $z$ were taken to imply $E_{t-1}$ $\left(p_{t-1}\right)=0$, then (21) would be unaltered but (22) would be $r-\frac{1}{\alpha_{1}} u$ $\frac{1+\alpha_{1}+\theta}{\alpha_{1}}\left(\frac{\phi}{\phi+\theta}\right) z$.

16. Fischer (1985) used a similar model assuming $\beta_{1}-1$ and $\theta-0$ to argue that the optimal money supply policy is unresponsive to supply disturbances, but that result is clearly a special case. For more general values of $\beta_{1}$ and $\theta, \frac{\mathrm{dm}}{\mathrm{d} z}$ may be positive or negative.

17. In other words, the solution shown here rests on the assumption that the three disturbances are independent.

18. As is familiar, in both cases $r-0$ shields $x$ from any disturbance to money 
demand, while $m=0$ exposes $x$ to the money demand disturbance but damps the spending disturbance.

19. Alternatively, the assumption $\ell-\min \left\{\ell^{s}, \ell^{\mathrm{d}}\right\}$ would lead to a criterion that switched according to $\ell^{\mathrm{d}} \gtrless \ell^{s}$.

20. The role of rigid nominal wages in providing this impediment to equilibrium (and hence a source of policy non-neutrality) makes clear the intimate connection between the problem of choosing a monetary policy instrument with the degree of wage indexation (here zero) taken as given, and the problem of choosing a wage indexation system with the conduct of monetary policy taken as given. This equivalence is explicit, for example, in Karn (1983), Aizenmann and Frenkel (1986) and Turnovsky (1987).

21. For example, Brunner and Meltzer (1964, 1972, 1976 and elsewhere) have consistently taken this approach

22. To be strictly accurate, what economists usually construe as nonborrowed reserves (or the nonborrowed monetary base) is not a quantity directly set by the central bank either. In the United States, for example, such technical factors as float, Treasury deposits at Federal Reserve Banks, Federal Reserve holdings of foreign currencies, gold flows, and accounts of foreign central banks all stand between the economist's concept and the quantity directly altered by the Federal Reserve's securities transactions Moreover, economists almost always refer to nonborrowed reserves on a seasonally adjusted basis, and on a basis adjusted to reflect changes in reserve requirements. Omitting such matters from attention in a survey 
like this reflects the usual presumption that, over whatever is the minimum time horizon that matters for macroeconomic purposes, the central bank can successfully offset such factors to within a tolerance sufficient to allow analysts outside the central bank to neglect them altogether.

23. As in the Poole analysis reviewed in Section $I$, in general the policy that minimizes the variance of income is to supply reserves with some non-zero yet finite elasticity.

24. With zero expectations for all three disturbances, the policy consistent with $E(m)=0$ would be just $r=0$ or $h=0$.

25. Specifically, the variance $E_{t-1}\left(y_{t}^{2}\right)$ that follows from (35) or (36) is in general greater than the corresponding variance given in (37) or (38). respectively.

- A plausible reason is that the analytical shortcomings of using money as an intermediate target variable were already known before the use of supply-demand models for the analysis of monetary policy issues became widespread.

27. Hall's (1984) work, discussed below, makes this concept explicit; some proponents of nominal income targeting appear to have based their advocacy of the idea on just this notion. Others, like Tobin (1983) and McCallum (1984), have relied more on the stochastic structure of aggregate supply behavior. See the discussion below. 
28. If the expectations of all disturbances are zero, then $r-0$ or $h-0$ implies $E(p)=E(x+p)=0$, and targeting prices or nominal income is indistinguishable from any other kind of policy.

29. The usual interpretation of an aggregate demand function like (41) is as a solved-out IS-LM system. If the underlying spending and money demand relations are as in (8) and (9), then (apart from price expectations) $\boldsymbol{\psi}=\frac{\alpha_{1}}{\mathrm{a}_{1} \beta_{1}+\beta_{2}}$ and $e-\frac{1}{\alpha_{1} \beta_{1}+\beta_{2}}\left(\beta_{2} \mathrm{u}-\alpha_{1} v\right)$. Alternatively, allowing for the endogeneity of money as in the analysis above based on the demand-only model would require writing (41) as $x-\psi\left(\delta_{1} h-p\right)+e$, which can similarly be interpreted as a solved-out version of (8), (9) and (31) where now $\psi-\frac{\alpha_{1}}{a_{1} \beta_{1}+\beta_{2}+\delta_{2}}$ and $e-\frac{\left(\beta_{2}+\delta_{2}\right) u-\alpha_{1}(v-q)}{\alpha_{1} \beta_{1}+\beta_{2}+\delta_{2}}$. Use of either version, of course, presumes that the central bank does not choose $r$ as the policy instrument.

30. The minimum value $\sum^{2}$ is in general non-zero because of the white-noise components of $z$ and $e$, and the one-period innovations to the random walk components of $z$ and $e$.

31. Bean did not consider the further problem associated with the endogeneity of most plausible definitions of "money." See again footnote 29.

32. West's result is both necessary and sufficient, while Bean's is merely sufficient, because of the simpler structure of West's model. Instead of (14), West used the aggregate supply function in (10), with adaptive price expectations as the device rendering monetary policy non-neutral. (West 
showed that it is the difference in objective, not the difference in supply behavior, which accounts for the difference between his result and Bean's.)

33. See for, example, Cooper and Fischer (1972a, 1972b).

34. Leroy and Waud (1977) made the dynamic nature of this approach still more explicit by drawing the analogy between the use of an information variable and Kalman filtering.

35. Tobin (1970) is the classic statement of the objection to money as an intermediate target based on questions of causation.

36. What remains, of course, is the question of whether the results of Granger-Sims tests, based on data from a sample in which the central bank conducted monetary policy under one set of principles, continue to be pertinent after a change in those principles. See Lucas (1976) and Sims (1982) for opposing viewpoints on this issue.

37. Hall's (1984) "elastic price standard" is an exception.

38. A further question in this context is why restrict the information variables to financial ones. Unlike the intermediate target strategy, the information variable strategy can in general be centered on nonfinancial variables. Although this point is familiar enough (see, for example, B. Friedman (1984a)), the literature to date has not explored in a formal way the possibility of feedback rules based explicitly on nonfinancial sources of information. 
39. It is also straightforward to calculate the optimal elasticity of reserves supply, analogous to Poole's optimal elasticity of money supply in (6), that will in general dominate either $r-0$ or $h=0$.

40. Because systematic monetary policy does not affect real variables in their model, the only basis for choosing a target value for the money stock is presumably to influence prices. The basic flaw in the intermediate target strategy still obtains, however.

41. A possible exception here is the large literature on institutional arrangements facilitating (more typically, impeding) the coordination of monetary and fiscal policies. That subject lies beyond the scope of this survey, however.

42. In most models the same conclusion would hold for the choice of a policy instrument to affect prices or (with a source of nonneutrality) income.

43. For example, the U.S. case which motivated McCallum and Hoehn's analysis involved a two-week lag. By contrast, the shortest time period introduced in macroeconomic discussions along the lines of ( 8$)-(10)$ is usually one calendar quarter, and it is often much longer. Subsequently, the Federal Reserve System shortened the lag to two days, but this change did not put an end to analysis of its operations as a lagged reserve requirement; see, for example, Goodfriend (1984).

44. Even so, given the traditional importance of this subject in both academic and practical discussions of monetary policy it is surprising how little 
literature has arisen examining such potential effects. Two exceptions are Johnson (1981) and Friedman (1982b).

45. See also Higgins (1982), Radecki (1984) and Lane (1984).

46. The basic point here is related to Lucas' (1976) criticism of economic policymaking based on econometric models, but here it is more general in form in that what changes is private agents' information sets. A more direct application of Lucas' point is Walsh's (1984) analysis of the consequences of the choice of instrument variable for money demand behavior.

47. In other words, no nominal rigidity provides a source of nonneutrality like that considered in Sections I and II.

48. See, for example, the discussion among B. Friedman (1984b), M. Friedman (1984) and McCallum (1984).

49. Conceptual antecedents of this procedure are Reuber (1964) and Friedlaender (1973). The switch to upper-case notation here reflects the fact that variables are not necessarily in logarithms, and do not necessarily bear the interpretation of deviations from deterministic base values.

50. For references to many of the specific contributions over the years, see again Cagan (1982) and McCallum (1985).

51. See, for example, the papers cited by Judd and Scadding (1982) and, more 
recently, Roley (1985).

52. See, for example, Pindyck and Roberts (1976).

53. See, for example, the empirical evidence presented by Simpson et al. (1979) in support of the Federal Reserve System's 1980 redefinition of the U.S. monetary aggregates.

54. Again see the review of these issues in Stanley Fischer's contribution to this Handbook. 
Aizenmann, Joshua, and Frenkel, Jacob A. "Optimal Wage Indexation, Foreign Exchange Intervention, and Monetary Policy." American Economic Review, 75 (June, 1985), 402-423.

Aizenmann, Joshua, and Frenkel, Jacob A. "Supply Shocks, Wage Indexation, and Monetary Accommodation." Journal of Money. Credit and Banking, 18 (August, 1986), 304-322.

Andersen, Leonall C., and Jordan, Jerry L. "Monetary and Fiscal Actions: A Test of Their Relative Importance in Economic Stabilization." Federal Reserve Bank of St. Louis, Economic Journal (November, 1968), $11-24$.

Ando, Albert, and Modigliani, Franco. "The Relative Stability of Monetary Velocity and the Investment Multiplier." American Economic Review, 55 (September, 1965a), 693-728.

Ando, Albert, and Modigliani, Franco, "Rejoinder." American Economic Review, 55 (September, 1965b), 786-790.

Barro, Robert J., and Gordon, David B. "Rules, Discretion, and Reputation in a Model of Monetary Policy." Journal of Monetary Economics, 12 (July, 1983). $101 \cdot 121$

Bean, Charles R. "Targeting Nominal Income: An Appraisal." Economic Journal, 93 (December, 1983), 806-819.

Bernanke, Ben S., and Gertler, Mark. "Agency Costs, Collateral, and Business Fluctuations." Mimeo: National Bureau of Economic Research, 1986.

Blinder, Alan S., and Stiglitz, Joseph E. "Money, Credit Constraints, and Economic Activity." American Economic Review, 73 (May, 1983), 297-302.

Brainard, William. "Uncertainty and the Effectiveness of Policy." American Economic Review, 57 (May, 1967), 411-425.

Brunner, Karl, and Meltzer, Allan H. "The Federal Reserve's Attachment to the Free Reserve Concept." U.S. Congress, House Committee on Banking and Currency, Subcommittee on Domestic Finance. 88 th Congress, 2nd Session. Washington: U.S. Government Printing office, 1964.

Brunner, Karl, and Meltzer, Allan H. "The Meaning of Monetary Indicators." Horwich (ed.), Monetary Process and Policy: Symposium. Homewood: Richard D. Irwin, 1967.

Brunner, Karl, and Meltzer, Allan H. "The Nature of the Policy Problem." Brunner (ed.), Targets and Indicators of Monetary Policy. San Francisco: Chandler Publishing Company, 1969.

Brunner, Karl, and Meltzer, Allan H. "Money, Debt, and Economic Activity." Journal of Political Economy, 80 (September/October, 1972), 951-977. 
Brunner, Karl, and Meltzer, Allan H. "An Aggregative Theory for a Closed Economy." Stein (ed.), Monetarism. Amsterdam: North-Holland Publishing Company, 1976.

Cagan, Phillip. "Monetarism in Historical Perspective." Mayer et al., The Structure of Monetarism. New York: W. W. Norton \& Company, 1978.

Cagan, Phillip. "The Choice Among Monetary Aggregates as Targets and Guides for Monetary Policy." Journal of Money, Credit, and Banking, 14 (November, 1982, Part 2), 661-686.

Ciccolo, John H. "Is Short-run Monetary Control Feasible?" Federal Reserve Bank of New York, Monetary Aggregates and Monetary Policy. New York: 1974 .

Cooper, J. Phillip, and Fischer, Stanley. "Simulations of Monetary Rules in the FRB-MIT-Penn Model." Journal of Money, Credit, and Banking, 4 (May, 1972 a), $384-396$.

Cooper, J. Phillip, and Fischer, Stanley. "Stochastic Simulation of Monetary Rules in Two Macroeconometric Models." Journal of the American Statistical Association, 67 (December, 1972b), 750-760.

Davis, Richard G. "Short-run Targets for Open Market Operations." Board of Governors of the Federal Reserve System, Open Market Policies and Operating Procedures .. Staff Studies. Washington: 1971.

DeRosa, Paul and Stern, Gary H. "Monetary Control and the Federal Funds Rate." Journal of Monetary Economics, 3 (April, 1977), 217-230.

Dotsey, Michael, and King, Robert $G$. "Informational Implications of Interest Rate Rules." American Economic Review, 76 (March, 1986), 33-42.

Enzler, Jared, and Johnson, Lewis. "Cycles Resulting from Money Stock Targeting." Board of Governors of the Federal Reserve System, New Monetary Control Procedures. Vol. I. Washington: 1981

Federal Reserve Bank of Boston. Controlling Monetary Aggregates. Boston: 1969 .

Fiege, Edgar L., and McGee, Robert. "Has the Federal Reserve Shifted from a Policy of Interest Rate Targets to a Policy of Monetary Aggregate Targets?" Journal of Money, Credit, and Banking, 11 (November, 1979), 381-404.

Freedman, Charles. "Some Theoretical Aspects of Base Control." Purvis (ed.). The Canadian Balance of Payments: Perspectives and Policy Issues Montreal: Institute for Research on Public Policy, 1983.

Fischer, Stanley, "Long-Term Contracts, Rational Expectations, and the Optimal Money Supply Role." Journal of Political Economy, 85 (February, 1977a), $91-205$.

Fischer, Stanley. "Long-term Contracting, Sticky Prices, and Monetary Policy: A Comment." Journal of Monetary Economics, 3 (July, 1977b), 317-323. 
Fischer, Stanley. "On Activist Monetary Policy with Rational Expectations." Fischer (ed.), Rational Expectations and Economic Policy. Chicago: University of Chicago Press, 1980.

Fischer, Stanley, "Supply Shocks, Wage Stickiness, and Accommodation." Journal of Money. Credit, and Banking, 17 (February, 1985), 1-15.

Friedlander, Anne F. "Macro Policy Goals and Revealed Preference." Quarterly Journal of Economics, 87 (February, 1973), 25-43.

Friedman, Benjamin M. "Targets, Instruments, and Indicators of Monetary Policy." Journal of Monetary Economics, 1 (October, 1975), 443-473.

Friedman, Benjamin M. "The Inefficiency of Short-run Monetary Targets for Monetary Policy." Brookings Papers on Economic Activity, (No. 2, 1977), $293-335$.

Friedman, Benjamin M. "Time to Reexamine the Monetary Targets Framework." Federal Reserve Bank of Boston, New England Economic Review (March/April, $1982 a), 15-23$.

Friedman, Benjamin M. "Federal Reserve Policy, Interest Rate Volatility, and the U.S. Capital Raising Mechanism." Journal of Money. Credit, and Banking, 14 (November, 1982b, Part 2), 721-745.

Friedman, Benjamin M. "The Roles of Money and Credit in Macroeconomic Analysis." Tobin (ed.), Macroeconomics. Prices and Quantities: Essays in Memory of Arthur M. Okun. Washington: The Brookings Institution, 1983.

Friedman, Benjamin M. "Lessons from the 1979-82 Monetary Policy Experiment." American Economic Review, 74 (May, 1984a), 382-387.

Friedman, Benjamin M. "The Value of Intermediate Targets in Implementing Monetary Policy." Federal Reserve Bank of Kansas City, Price Stability and Public Policy. Kansas City: $1984 \mathrm{~b}$.

Friedman, Benjamin M., and Kuttner, Kenneth N. "Money, Income and Prices After the 1980s." Mimeo: National Bureau of Economic Research, 1988.

Friedman, Milton. "The Effects of a Full-Employment Policy on Economic Stability: A Formal Anlysis." Friedman, Essays in Positive Economics. Chicago: University of Chicago Press, 1953.

Friedman, Milton. "Lessons from the 1979-82 Monetary Policy Experiment." American Economic Review, 74 (May, 1984), 397-400.

Friedman, Milton, and Meiselman, David. "The Relative Stability of Monetary Velocity and the Investment Multiplier in the United States, 1897-1958." Commission on Money and Credit, Stabilizations Policies. Englewood Cliffs: Prentice-Hall, 1963.

Friedman, Milton, and Meiselman, David. "Reply to Ando and Modigiliani and to DePrano and Mayer." American Economic Review, 55 (September, 1965), $753-785$. 
Friedman, Milton, and Schwartz, Anna Jacobson. A Monetary History of the United States, 1867-1960. Princeton: Princeton University Press, 1963.

Goodfriend, Marvin. "Discount Window Borrowing, Monetary Policy, and the postOctober 6, 1979 Federal Reserve Operating Procedure." Journal of Monetary Economics, 12 (September, 1983), 343-356.

Goodfriend, Marvin. "The Promises and Pitfalls of Contemporaneous Reserve Requirements for the Implementation of Monetary Policy." Federal Reserve Bank of Richmond, Economic Review, 70 (May/June, 1984), 3-12.

Granger, Clive W. J. "Investigating Causal Relations by Econometric Models and Cross Spectral Methods." Econometrica, 37 (July, 1969), 424-438.

Gray, Jo Anna. "Wage Indexation: A Macroeconomic Approach." Journal of Monetary Economics, 2 (April, 1976), 221-235.

Guttentag, Jack F. "The Strategy of Open Market Operations." Quarterly Journal of Economics, 80 (February, 1966), 1-30.

Hall, Robert E. "Monetary Policy with an Elastic Price Standard." Federal Reserve Bank of Kansas City, Price Stability and Public Policy. Kansas City: 1984 .

Higgins, Bryon. "Should the Federal Reserve Fine Tune Monetary Growth?" Federal Reserve Bank of Kansas City, Economic Review (January, 1982), 3-16.

Hoehn, James G. "Recent Monetary Control Procedures and the Response of Interest Rates to Fluctuations in Money Growth." Federal Reserve Bank of Dallas, Economic Review (September, 1983), 1-10.

Holbrook, Robert S. "Optimal Economic Policy and the Problem of Instrument Instability." American Economic Review, 62 (March, 1972), 57-65.

Johannes, James M., and Rasche, Robert H. "Predicting the Money Multiplier." Journal of Monetary Economics, 5 (July, 1979), 301-325.

Johnson, Dana, and others. "Interest Rate Variability under the New Operating Procedures and the Initial Response in Financial Markets." Board of Governors of the Federal Reserve System, New Monetary Control Procedures. Vol. I. Washington: 1981 .

Judd, John P., and Scadding, John L. "The Search for a Stable Money Demand Function: A Survey of the Post-1973 Literature." Journal of Economic Literature, 20 (September, 1982), 993-1023.

Kareken, John H., Muench, Thomas, and Wallace, Ne11. "Optimal Open Market Strategy: The Use of Information Variables." American Economic Review, 63 (March, 1973), 156-172.

Karni, Edi. "On Optimal Wage Indexation." Journal of Political Economy, 91 (Apri1, 1983), 282-292.

King, Robert G. "Monetary Policy and the Information Content of Prices." 
Journal of Political Economy, 90 (Apri1, 1982), 247-279.

King, Robert G. "On the Economics of Private Money." Journal of Monetary Economics, 12 (July, 1983), 127-185.

Kydland, Finn E., and Prescott, Edward C. "Rules Rather than Discretion: The Inconsistency of Optimal Plans." Journal of Political Economy, 85 (June, 1977), 473-491.

Lane, Timothy D. "Instrument Instability and Short-term Monetary Control." Journal of Monetary Economics, 14 (September, 1984), 209-224.

LeRoy, Stephen F., and Waud, Roger N. "Applications of the Kalman Filter in Short-Run Monetary Control." International Economic Review, 18 (February, 1977), 195-207.

Levin, Fred, and Meek, Paul. "Implementing the New Procedures: The View from the Trading Desk." Board of Govenors of the Federal Reserve System, New Monetary Control Procedures. Vol. I. Washington: 1981.

Lombra, Raymond, and Moran, Michael. "Policy Advice and Policymaking at the Federal Reserve." Brunner and Meltzer (eds.), Monetary Institutions and the Policy Process. Amsterdam: North-Holland Publishing Company, 1980.

Lombra, Raymond E., and Torto, Raymond G. "Discount Rate Changes and Announcement Effects." Quarterly Journal of Economics, 91 (February, 1977), $171-176$.

Lucas, Robert E., Jr. "Expectations and the Neutrality of Money." Journal of Economic Theory, 4 (April, 1972), 103-124.

Lucas, Robert E., Jr. "Some International Evidence on Output-Inflation Tradeoffs." American Economic Review, 63 (June, 1973), 326-334.

Lucas, Robert E., Jr. "Econometric Policy Evaluation: A Critique." Brunner and Meltzer (eds.). The Phillips Curve and Labor Markets. Amsterdam: North-Holland Publishing Company, 1976.

McCallum, Bennett T. "Price Level Determinancy with an Interest Rate Policy Rule and Rational Expectations." Journal of Monetary Economics, 8 (November, 1981), 319-329.

McCallum, Bennett T. "Monetarist Rules in the Light of Recent Experience." American Economic Review, 74 (May, 1984) 388-391.

McCallum, Bennett T. "On Consequences and Criticisms of Monetary Targeting." Journal of Money. Credit, and Banking, 17 (November, 1985, Part 2), 570-597.

McCallum, Bennett $T$. and Hoehn, James G. "Instrument Choice for Money Stock Control with Contemporaneous and Lagged Reserve Requirements." Journal of Money. Credit, and Banking, 15 (February, 1983), 96-101.

Modigliani, Franco. "The Monetary Mechanism and its Interaction with Real 
Phenomena." Review of Economics and Statistics, 45 (February, 1963, Part 2), 79-107.

Modigliani, Franco, Rasche, Robert, and Cooper, J. Phillip. "Central Bank Policy, the Money Supply, and the Short-term Rate of Interest." Journal of Money. Credit, and Banking, 2 (May, 1970), 166-218.

Modigliani, Franco, and Papademos, Lucas D. "The Structure of Financial Markets and the Monetary Mechanism." Federal Reserve Bank of Boston. Controlling Monetary Aggregates III. Boston: 1983.

Patinkin, Don. Money. Interest, and Prices; an Integration of Monetary and Value Theory. New York: Harper and Row, 1965.

Phelps, Edmund S., and Taylor, John B. "Stabilizing Powers of Monetary Policy Under Rational Expectations." Journal of Political Economy, 85 (February, 1977), $163 \cdot 190$.

Pierce, James L., and Thomson, Thomas D. "Some Issues in Controlling the Stock of Money." Federal Reserve Bank of Boston, Controlling Monetary Aggregates II: The Implementation. Boston: 1972 .

Pindyck, Robert S., and Roberts, Steven M. "Instruments, Intermediate Targets, and Monetary Controllability." International Economic Review, 17 (October, 1976), 627-650.

Poole, William "Optimal Choice of Monetary Policy Instrument in a Simple Stochastic Macro Model." Quarterly Journal of Economics, 84 (May, 1970), 197-216.

Poole, William. Comments on James Tobin, "Stabilization Policy Ten Years After." Brookings Papers, on Economic Activity (No. 1, 1980), 79-85.

Poole, William, and Lieberman, Charles. "Improving Monetary Control." Brookings Papers on Economic Activity (No. 2, 1972), $293-335$.

Radecki, Lawrence J. "Targeting in a Dynamic Model." Federal Reserve Bank of New York, Quarterly Review (Summer 1984), 9-15.

Reuber, Grant L. "The Objectives of Canadian Monetary Policy, 1949-61: Empirlcal 'Trade-offs' and the Reaction Function of the Authorities." Journal of Political Economy, 72 (April, 1964), 109-132.

Roley, Vance. "Money Demand Predlctability." Journal of Money, Credit, and Banking, 17 (November, 1985, Part 2), 611-641.

Santomero, Anthony M. "Controlling Monetary Aggregates: The Discount Window." The Journal of Finance, 38 (June, 1983), 827-844.

Sargent, Thomas J., and Wallace, Neil. "Rational Expectations, the Optimal Monetary Instrument, and the Optimal Money Supply Rule." Journal of Political Economy, 83 (April, 1975), 241-254.

Siegel, Jeremy J. "Monetary Aggregates as Indicators of Economic Activity: 
A Theoretical Analysis." Mimeo. University of Pennsylvania, 1985.

Simpson. Thomas D., et al. "A Proposal for Redefining the Monetary Aggregates." Federal Reserve Bulletin, 65 (January, 1979), $13-42$.

Sims, Christopher A. "Money, Income, and Causality." American Economic Review, 62 (September, 1972), 540-552.

Sims, Christopher A. "Policy Analysis with Econometric Models." Brookings Papers on Economic Activity. (No. 1, 1982), 107-152.

Taylor, John B. "What Would Nominal Income Targetting Do to the Business Cycle?" Brunner and Meltzer (eds.), Understanding Monetary Regimes. Amsterdam: North-Holland Publishing Company, 1985.

Tinbergen, Jan. On the Theory of Economics Policy. Amsterdam: North-Holland Publishing Co., 1952 .

Tinsley, Peter A., Fries, Gerhard, Garrett, Bonnie, and von zur Muehlen, Peter. "Appendix C - Estimated Monetary Policy Consequences of Reserve Accounting Procedures." Mimeo: Federal Reserve Board, September, 1981

Tobin, James. "Money and Income: Post Hoc Ergo Propter Hoc?" Quarterly Journal of Economics, 84 (May, 1970), 301-317.

Tobin, James. "Monetary Policy: Rules, Targets, and Shocks." Journal of Money, Credit, and Banking, 15 (November, 1983), 506-518.

Turnovsky, Stephen J. "Supply Shocks and Optimal Monetary Pollcy." Oxford Economic Papers, 39 (March, 1987), 20-37.

Walsh, Carl E. "Interest Rate Volatility and Monetary Policy." Journal of Money. Credit, and Banking, 16 (May, 1984), 133-150.

West, Kenneth D. "Targeting Nominal Income: A Note." Mimeo: National Bureau for Economic Research, 1986. 